\title{
Wolbachia infection in Argentinean populations of Anastrepha fraterculus sp1: preliminary evidence of sex ratio distortion by one of two strains
}

Claudia Alejandra Conte ${ }^{1}$, Diego Fernando Segura ${ }^{1,2}$, Fabian Horacio Milla ${ }^{1}$, Antonios Augustinos ${ }^{3}$, Jorge Luis Cladera ${ }^{1}$, Kostas Bourtzis ${ }^{3}$ and Silvia Beatriz Lanzavecchia ${ }^{{ }^{*}}$

\begin{abstract}
Background: Wolbachia, one of the most abundant taxa of intracellular Alphaproteobacteria, is widespread among arthropods and filarial nematodes. The presence of these maternally inherited bacteria is associated with modifications of host fitness, including a variety of reproductive abnormalities, such as cytoplasmic incompatibility, thelytokous parthenogenesis, host feminization and male-killing. Wolbachia has attracted much interest for its role in biological, ecological and evolutionary processes as well as for its potential use in novel and environmentallyfriendly strategies for the control of insect pests and disease vectors including a major agricultural pest, the South American fruit fly, Anastrepha fraterculus Wiedemann (Diptera: Tephritidae).

Results: We used wsp, 165 rRNA and a multilocus sequence typing (MLST) scheme including gatB, coxA, hcpA, fbpA, and ftsZ genes to detect and characterize the Wolbachia infection in laboratory strains and wild populations of $A$. fraterculus from Argentina. Wolbachia was found in all A. fraterculus individuals studied. Nucleotide sequences analysis of wsp gene allowed the identification of two Wolbachia nucleotide variants (named wAfraCast1_A and wAfraCast2_A). After the analysis of 76 individuals, a high prevalence of the wAfraCast2_A variant was found both, in laboratory (82\%) and wild populations (95\%). MLST analysis identified both Wolbachia genetic variants as sequence type 13. Phylogenetic analysis of concatenated MLST datasets clustered wAfraCast1/2_A in the supergroup A. Paired-crossing experiments among single infected laboratory strains showed a phenotype specifically associated to wAfraCast1_A that includes slight detrimental effects on larval survival, a female-biased sex ratio; suggesting the induction of male-killing phenomena, and a decreased proportion of females producing descendants that appears attributable to the lack of sperm in their spermathecae.

Conclusions: We detected and characterized at the molecular level two wsp gene sequence variants of Wolbachia both in laboratory and wild populations of A. fraterculus sp.1 from Argentina. Crossing experiments on singlyinfected $A$. fraterculus strains showed evidence of a male killing-like mechanism potentially associated to the wAfraCast1_A - A. fraterculus interactions. Further mating experiments including antibiotic treatments and the analysis of early and late immature stages of descendants will contribute to our understanding of the phenotypes elicited by the Wolbachia variant WAfraCast1_A in A. fraterculus sp.1.
\end{abstract}

Keywords: Endosymbiont, Fruit fly, MLST, Wsp, 165 rRNA, Sex ratio

\footnotetext{
* Correspondence: lanzavecchia.silvia@inta.gob.ar

${ }^{1}$ Laboratorio de Insectos de Importancia Agronómica, IGEAF, Instituto

nacional de Tecnología Agropecuaria (INTA) gv IABIMO-CONICET,

Hurlingham, Buenos Aires, Argentina

Full list of author information is available at the end of the article
}

(C) The Author(s). 2019 Open Access This is an open access article distributed under the terms of the Creative Commons Attribution IGO License (https://creativecommons.org/licenses/by/3.0/igo/) which permits unrestricted use, distribution, and reproduction in any medium, provided appropriate credit to the original author(s) and the source is given. 


\section{Background}

Wolbachia constitutes a diverse group of maternally inherited endosymbionts belonging to the Alphaproteobacteria [1, 2]. To date, 16 different Wolbachia supergroups (A-F and $\mathrm{H}-\mathrm{Q}$ ) have been described [3]. Genomic approaches have been used to classify some of these Wolbachia supergroups as different species [4, 5], although this is still a rather controversial issue [6]. Supergroups A and B are widely spread across many arthropod taxa [7], C and D are found exclusively in filarial nematodes [8] whereas $\mathrm{E}$ is found in springtails [9]. Other Wolbachia supergroups are found in different host species. For instance, F supergroup comprises Wolbachia from termites, weevils, true bugs and scorpions $[10,11]$. Different genetic markers have been employed to classify Wolbachia in supergroups including the $16 \mathrm{~S}$ ribosomal RNA (16S rRNA) and the Wolbachia surface protein $(w s p)$ genes [12-14]. More recently, two multi locus sequence typing (MLST) approaches and a $w s p$ based system have been developed for genotyping in addition to phylogenetic and evolutionary analyses of this bacterial taxonomic group $[15,16]$. The discovery of supergroups (H-P) is mainly based on the full-length sequence of the $16 S$ rRNA and additional gene markers, such as groEL (heat-shock protein 60), gltA (citrate synthase) and fts Z (cell division protein) [17]. This is in most cases associated to the lack of positive results (PCR amplification and/or sequencing) of any of the MLST genes in diverse supergroups (see also [3, 18-20]).

Wolbachia infections have been reported in the somatic tissues of a wide range of arthropod hosts [21, 22] and filarial nematodes $[8,23,24]$. However, they are mainly known to reside in reproductive tissues and organs [21, 25-27]. In arthropods, Wolbachia often behave as reproductive parasites by manipulating the host reproduction to enhance its own vertical transmission [28] giving a reproductive advantage to infected individuals and spreading Wolbachia through natural populations [29-33]. A wide range of reproductive alterations induced by Wolbachia infection has been described in host species, including cytoplasmic incompatibility $(\mathrm{CI})$, parthenogenesis, feminization and malekilling (MK) [1, 2, 34-36]. CI is the most common phenotype induced by Wolbachia and is characterized by the induction of an embryonic lethality causing mating incompatibility in the crosses between Wolbachia infected males and uninfected females (unidirectional CI). Similar physiological incompatibilities are observed in crosses between individuals infected by mutually-incompatible Wolbachia strains (bidirectional CI) [35, 37-39]. Parthenogenesis is another well-documented Wolbachia-induced mechanism in haplodiploid species by which the bacterium 'forces' unfertilized eggs to develop into females rather than males [40, 41]. Wolbachia-mediated feminization is characterized by the development of infected males into fertile females. This phenotype has been observed in both insects and isopods [42-44]. MK is expressed as male lethality during development resulting in a female-biased sex ratio $[36,45$, 46]. MK can be elicited early during the embryonic development, or late in the larval or pupal stage [47]. MK is not limited to Wolbachia, as this phenomenon has been described for at least five clades of bacteria associated to the reproductive system (Additional file 1).

Wolbachia-host symbiotic associations are rather complex, since this reproductive microorganism can also be associated with a variety of additional phenotypes. These traits include the protection of insect hosts against pathogens and parasites [48-53], mating preference [54-56] and the response to olfactory cues [57]. The unique biology of Wolbachia has been explored for the development of novel strategies for the control of pests and diseases [33, 58-61]. For example, it has been shown that the Incompatible Insect Technique (IIT), which is based on the mechanism of Wolbachia-induced CI, can be used alone or in combination with the Sterile Insect Technique (SIT) to suppress populations of insect pests of agricultural, veterinary or human health importance [58, 62-67]. Wolbachia-induced MK has also been suggested as a tool for insect pest control $[68,69]$.

The South American fruit fly, Anastrepha fraterculus Wiedemann (Diptera: Tephritidae) is a complex of cryptic species [70-73] that is distributed in subtropical and temperate regions of the American continent, covering a wide geographical range from the United States of America to Argentina [74-76]. Recent studies focused on the elucidation of species from the A. fraterculus complex have followed an integrative approach. These scientific works addressed this taxonomic issue using different strategies based on morphology [73, 77], behavior and reproductive isolation [76, 78-81], and cytology and genetics [82-86]. Based on mating compatibility studies [87-89] and population genetic analysis [90, 91], a sinof the $A$. fraterculus complex was identified in Argentina and southern Brazil. This taxon has been named $A$. fraterculus sp.1 by Selivon et al. [82] and Brazilian-1 morphotype by Hernández-Ortiz et al. [73]. The presence of Wolbachia has been described in Brazilian populations and in laboratory colonies of $A$. fraterculus from Argentina and Peru [79, 82, 92]. In addition, a recent publication [93] showed the presence of Wolbachia in A. fraterculus populations belonging to different morphotypes across America.

In the present study, we initiated a comprehensive study to detect and characterize Wolbachia infections in A. fraterculus from Argentina including a laboratory colony and three wild populations. After the detection and molecular characterization of the symbiont, we raised the hypothesis that Wolbachia infection may be associated with the induction of reproductive phenotypes, 
which could be a contributing factor in the speciation of A. fraterculus species complex. This hypothesis was tested with a series of crossing experiments assessing pre- or post-mating incompatibility, and these phenomena are discussed.

\section{Materials and methods}

\section{Samples collection and DNA isolation}

Wild $A$. fraterculus individuals were obtained from infested fruits collected in three different localities of Argentina: Horco Molle (Tucumán province); Villa Zorraquín (Entre Ríos province) and Puerto Yeruá (Entre Ríos province) (Table 1). Larvae and pupae obtained from each locality were maintained under standard laboratory conditions [94, 95] until emergence. In addition, individuals from the laboratory colony reared at IGEAF (INTA-Castelar, Buenos Aires, Argentina) were obtained, processed and stored under the same conditions until DNA extraction (Table 1). A. fraterculus IGEAF strain was established in 2007 with approximately 10,000 pupae from the semi-mass rearing colony kept at Estación Experimental Agroindustrial Obispo Colombres, San Miguel de Tucumán, Tucumán, Argentina [96] and maintained to date (70 generations) under artificial rearing.

All insects were washed with TE buffer $(10 \mathrm{mM}$ Tris$\mathrm{HCl}, 10 \mathrm{mM}$ EDTA, $\mathrm{pH}$ 8) and stored at $-20^{\circ} \mathrm{C}$ until DNA extraction. Total DNA was individually isolated from adult flies (whole body) based on the protocol described by Baruffi et al. [97]. The quality of DNA samples was tested by electrophoresis in agarose gels $0.8 \% \mathrm{w} / \mathrm{v}$ in buffer TBE $0.5 \mathrm{X}$ and stained with ethidium bromide [98]. Images were captured with an UVP reveler (Fotodyne Inc. Hartland, WI, USA). Quality and quantity of DNA samples were also analyzed with Nanodrop 1000 (Thermo Scientific).

\section{Detection and genotyping of Wolbachia strains}

Wolbachia detection was based on the amplification and sequencing of a $16 S$ rRNA gene fragment (438 bp) using the Wolbachia-specific primers wspecF and wspecR [99] and a $w s p$ gene fragment (590 to $632 \mathrm{bp}$ long) using primers $81 \mathrm{~F} /$ 691R [13]. The sequence characterization of a wsp gene from each Wolbachia-nucleotide variant found in this study was performed by wsp hypervariable regions (HVRs) analysis using the Wolbachia MLST database (pubmlst.org/Wolba chia). HVR alleles were determined based on comparisons among available translated nucleotide sequences [100].
Laboratory colony (37 individuals; 24 females, 13 males) and insects from natural populations (39 individuals; 22 females, 17 males) were analyzed. A subset of DNA samples (Table 1) were genotyped using the MLST scheme proposed by Baldo et al. [15] to characterize Wolbachia. Partial regions of gat B (aspartyl/glutamyltRNA(Gln) amidotransferase, subunit B), coxA (cytochrome c oxidase, subunit I), hcpA (conserved hypothetical protein), $f b p \mathrm{~A}$ (fructose-bisphosphate aldolase) and ftsZ genes were amplified, using the standard protocols provided in the Wolbachia MLST database [15]. PCR products were purified using a Wizard SV Gel and PCR Clean-Up System (Promega) and forward and reverse sequences were obtained using an Abi 3130XL Genetic Analyzer (Applied Biosystem, SIGYSA- INTA, Argentina). Sequences were manually edited and aligned using Bioedit 7.0.9.0 [101] and Staden Package [102].

A Neighbor-joining tree was reconstructed based on the concatenated MLST datasets $(g a t \mathrm{~B}, \operatorname{cox} \mathrm{A}, h c p \mathrm{~A}, f b p \mathrm{~A}$ and ftsZ; 2079 bases long) using sequences generated in the present study and a batch of representative nucleotide sequences belonging to A, B and D Wolbachia supergroups published by Baldo and Werren [103] available through the Wolbachia MLST webpage. The phylogenetic tree was constructed using Mega Version 5.1 software [104] based on the Jukes and Cantor [105] genetic distance model after 1000 bootstrap resamples.

Seven additional gene markers previously described for the genotyping of Wolbachia were utilized to distinguish Wolbachia genetic variants infecting the A. fraterculus Argentinean populations. Partial regions of groEL and gltA [17], dnaA (Chromosomal replication initiator protein) [106], aspC (aspartate aminotransferase) atpD (ATP synthase) sucB (dihydrolipoamide succinyltransferase) and $p d h \mathrm{~B}$ (E1 component of the pyruvate dehydrogenase complex) [16] genes were amplified using primer sequences and PCR conditions described by the cited authors. At least three individuals of each $A$. fraterculus IGEAF strain harboring different genetic variants of Wolbachia were analyzed.

\section{Detection of other reproductive symbionts}

A. fraterculus DNA samples were also screened for the presence of other reproductive symbionts (Spiroplasma $s p$. [107], Cardinium sp. [108], Rickettsia sp. [109], Arsenophonus

Table 1 Sampling locations and number of individuals used for Wolbachia characterization

\begin{tabular}{|c|c|c|c|c|c|}
\hline Population ID & Coordinates & $w s p$ & $16 S$ rRNA & MLST & Additional markers $^{a}$ \\
\hline Horco Molle (Tucumán) & $26^{\circ} 46^{\prime} 48^{\prime \prime} \mathrm{S} 65^{\circ} 19^{\prime} 12^{\prime \prime} \mathrm{W}$ & 14 & 14 & 4 & 4 \\
\hline Villa Zorraquín (Entre Ríos) & $31^{\circ} 19^{\prime} 0.12^{\prime \prime} \mathrm{S} 58^{\circ} 1^{\prime} 59.88^{\prime \prime} \mathrm{W}$ & 10 & 10 & 3 & 3 \\
\hline Puerto Yeruá (Entre Ríos) & $31^{\circ} 31^{\prime} 53^{\prime \prime S} 58^{\circ} 00^{\prime} 55^{\prime \prime} \mathrm{W}$ & 15 & 15 & 5 & 5 \\
\hline IGEAF strain (Castelar, Buenos Aires) & $34^{\circ} 36^{\prime} 25.193^{\prime \prime} \mathrm{S} 58^{\circ} 40^{\prime} 2.699^{\prime \prime} \mathrm{W}$ & 37 & 37 & 10 & 10 \\
\hline
\end{tabular}

${ }^{\mathrm{a} A d d i t i o n a l ~ m a r k e r s:}$ groE, gltA, dnaA, aspC, atpD, sucB and $p d h \mathrm{~B}$ 
sp. [110] and Hamiltonella sp. [111]) using the primers and conditions described by the authors cited in Table 2 . In case of successful amplification, PCR products of expected size (according to the previously published works) were purified and sequenced.

New DNA sequences were deposited in public databases as is described in "Availability of data and material" section.

\section{Establishment of $A$. fraterculus Af-Cast-1 and Af-Cast-2 strains}

At least 20 single pairs (female and male) from $A$. fraterculus IGEAF strain (IGEAF, INTA Castelar, Argentina) were maintained in standard conditions $\left(25^{\circ} \mathrm{C}\right.$ temperature; $50 \%$ humidity and 12:12 Light: dark photoperiod) from the day of emergence to ensure that flies were virgin, since A. fraterculus reaches sexual maturity between 4 and 10 days after emergence [112]. At day 10 after emergence, egg collection devices (described by Vera et al. [94]) were offered to each couple continuously, either for a month or until at least 100 eggs were obtained. Total DNA was individually extracted from the parents of the families to determine the Wolbachia wsp nucleotide variant present in each one of them by PCR and sequencing of the amplicon as described above. Families sharing the same Wolbachia nucleotide variant (either wAfraCast1_A or $w$ AfraCast2_A) were pooled and maintained as discrete strains under laboratory conditions of rearing. These $A$. fraterculus strains were named Af-Cast-1 and Af-Cast-2.

\section{Evaluation of Wolbachia genomic integration in $A$. fraterculus}

The two laboratory strains of $A$. fraterculus (Af-Cast- 1 and Af-Cast-2 strains) were treated with antibiotics. Eggs were deposited in plastic containers with larval diet [95] containing $0.01 \%$ rifampicin (Richet). After adult emergence, $\mathrm{Wol}$ bachia infection status was assessed by wsp and $16 S$ rRNA based PCR assays using the specific primers described above. DNA extracted from individuals of the Af-Cast-1 and Af-Cast-2 A. fraterculus strains reared without antibiotic treatment was used as a positive control.

Singly-infected $A$. fraterculus strains (Af-Cast-1 or AfCast-2) were maintained in our laboratory under standard rearing conditions [94].

Table 2 Additional primers used for the detection of Wolbachia and other symbionts

\begin{tabular}{|c|c|c|c|}
\hline Species/Gene marker & Primer & Primer sequences $\left(5^{\prime}-3^{\prime}\right)$ & Amplicon size (bp) \\
\hline \multirow[t]{2}{*}{ Wolbachia/groE } & WgroF1 & GGTGAGCAGTTGCAAGAAGC & 846 \\
\hline & Wgro Rev1 & AGATCTTCCATCTTGATTCC & \\
\hline \multirow[t]{2}{*}{ Wolbachia/gltA } & WgltAF1 & TACGATCCAGGGTTGTTTCTAC & 554 \\
\hline & WgltARev1 & CTCATTAGCTCCACCGTGTG & \\
\hline \multirow[t]{2}{*}{ Wolbachia/dnaA } & dnaA2F & ACAATTGGTTATATCAGCTG & 378 \\
\hline & dnaA2R & TACATAGCTATTTGYCTTGG & \\
\hline \multirow[t]{2}{*}{ Wolbachia/aspC } & aspC49_F & ATYGCTGTRACYGATAAGGYAA & 818 \\
\hline & aspC1134R & AGARGTWGCATAAGARATTCTRA & \\
\hline \multirow[t]{2}{*}{ WolbachialatpD } & atpD242F & ATAYAGTKCGTTGTATTGCTATG & 881 \\
\hline & atpD1210R & CWTCAGAYAGYTCATCCATAC & \\
\hline \multirow[t]{2}{*}{ Wolbachia/sucB } & sucB358F & AAAGGRACTGGYATGGGARG & 612 \\
\hline & sucB981R & TGHGGAGGRTTWATWATCGG & \\
\hline \multirow[t]{2}{*}{ Wolbachia/pdhB } & pdhB86F & ARGAAGTTGCVGARTATSAWGG & 642 \\
\hline & pdhB812R & GCAAAWRRCCAWCCTTCTTCTA & \\
\hline \multirow[t]{2}{*}{ Spiroplasma sp./16S rRNA } & SpoulF & GCTTAACTCCAGTTCGCC & 421 \\
\hline & SpoulR & СCTGTCTCAATGTTAACCTC & \\
\hline \multirow[t]{2}{*}{ Cardinium sp./16S rRNA } & Ch-F & TACTGTAAGAATAAGCACCGGC & 463 \\
\hline & Ch-R & GTGGATCACTTAACGCTTTCG & \\
\hline \multirow[t]{2}{*}{ Rickettsia sp./gltA } & RicCS-AF & TTTAGGCTAATGGGTTTGGTCAT & 382 \\
\hline & RicCS-AR & TGCCCAAGTTCTIITAACACCTC & \\
\hline \multirow[t]{2}{*}{ Arsenophonus sp./16S rRNA } & ArsF & GGGTTGTAAAGTACTTTCAGTCGT & $581-804$ \\
\hline & ArsR2 & GTAGCCCTRCTCGTAAGGGCC & \\
\hline \multirow[t]{2}{*}{ Hamiltonella sp./16S rRNA } & HamF & TGAGTAAAGTCTGGAATCTGG & 700 \\
\hline & HamR & AGTTCAAGACCGCAACCTC & \\
\hline
\end{tabular}




\section{Mating experiments}

In order to detect whether the presence of Wolbachia is associated with reproductive isolation, we carried out mating tests crossing A. fraterculus strains Af-Cast- 1 and Af-Cast-2. Pre-zygotic isolation (which occurs before fertilization of gametes) as well as post-zygotic isolation (which occurs after fertilization) tests were performed as described below.

\section{Pre-zygotic isolation test}

Individual crosses in every possible combination (i.e., female $\mathrm{x}$ male: Af-Cast- 1 x Af-Cast-1, Af-Cast-1 x Cast-2, Af-Cast- $2 \times$ Af-Cast- 1 and Af-Cast- 2 x Af-Cast-2) were carried out in no-choice mating arenas under laboratory conditions following standard procedures [113]. Each arena consisted of a $1 \mathrm{~L}$ plastic cylindrical container with a screen lid. The day before the test, 10 day-old (sexually mature) and virgin males were individually transferred to the mating arenas with no food or water. The next morning, under semidarkness, 15 day-old (sexually mature) and virgin females were released in the experimental arenas. Once the experiment was set up, the room lights were turned on (8:30 am). Experiments were conducted under laboratory conditions ( $\mathrm{T}: 25 \pm 1{ }^{\circ} \mathrm{C}$ and $70 \pm 10 \% \mathrm{RH}$ ). The number of replicates was $59 \pm 5$ per cross type. The number of mated couples (percentage of mating), latency to mate and mating duration time were recorded for each type of cross. After the mating trial was completed, flies were removed from the mating arenas. Mated flies were preserved for post-zygotic tests (see below) whereas unmated flies were stored at $-20^{\circ} \mathrm{C}$.

\section{Post-zygotic isolation test}

Mated couples were maintained with food and water under controlled conditions and allowed to lay eggs in an artificial egg-laying device. Eggs were collected, placed on a piece of black filter paper, counted and transferred to Petri dishes (3 cm diameter) with larval diet $[94,95]$. The Petri dishes were placed in a larger container on top of a layer of vermiculite (pupation substrate). After 5 days, the number of hatched eggs was recorded. After all developing larvae had exited the diet and pupated in the vermiculite pupae were collected, counted and placed under controlled conditions until emergence. The number and sex of emerged adults from each cross were recorded. Once the post-zygotic test ended, parental flies were stored at $20^{\circ} \mathrm{C}$ and subsequently checked for the presence of $\mathrm{Wol}$ bachia (using the wsp-based PCR assay described above).

Ten F1 couples from each family (sibling mating) were randomly selected and kept under standard laboratory conditions with food and water and allowed to lay eggs to obtain F2, following the procedures described above for the parental generation.

\section{Data analysis}

The percentage of mating recorded in the pre-zygotic test was compared among the four types of crosses by means of a chi-square test of homogeneity. The latency to mate and the mating duration time were compared among treatments using a one-way analysis of variance (ANOVA) followed by a post hoc Tukey's multiple comparisons test.

Post-zygotic tests involved the analysis of the following parameters both in F1 and F2 generations: \% of egg hatch (number of hatched eggs/total number of eggs*100); \% of pupation (number of recovered pupae/number of eclosed larvae ${ }^{*} 100$ ); \% of adult emergence (number of emerged adults/number of recovered pupae $\left.{ }^{*} 100\right)$; female sex ratio (number of adult females/number of emerged adults). These variables were analyzed by means of a one-way ANOVA. Normality and homoscedasticity assumptions were met for all variables, except for the percentage of pupation in the F1. In this case, data were arcsine square transformed to meet homogeneity of variances assumptions. In all cases, ANOVA were followed by post hoc Tukey's multiple comparisons tests. Deviations from a 0.5 sex ratio were evaluated by means of a G-test of goodness of fit, applying the Bonferroni correction for multiple comparisons.

Additionally, we analyzed: 1. Percentage of mated females that produced eggs (number of females that laid > 10 eggs/number of mated females*100); 2. Percentage of females that produced viable eggs (number of females for which $>5 \%$ of eclosed eggs were found / number of females that produced eggs*100); 3 . Percentage of females with descendants (number of females which produced $>5$ emerged F1 adults/number of females that produced viable eggs *100); 4. Percentage of mated females that produced viable eggs (number of females for which $>5 \%$ of eclosed eggs were found/number of mated females*100; i.e., considering all mated females); 5. Percentage of mated females with descendants (number of females which produced $>5$ emerged F1 adults/ number of mated females *100; i.e., considering all mated females). These variables were compared among types of crosses by means of a Chi-Square test of homogeneity; first among the four types of crosses, and later between Af-Cast-1 and Af-Cast- 2 females.

Statistical analyses were performed using STATISTICA for Windows [114].

\section{Cytological analysis}

Mated females that did not produce descendants (females that did not lay eggs or that laid unviable eggs) were dissected under a stereoscope microscope (Olympus SZ30, Tokyo, Japan) to check both for any developmental abnormalities in the ovaries and the presence of sperm in spermathecae. The two ovaries and three spermathecae 
from each female were removed and placed on a slide. Preparations were stained with $2 \%$ acetic-orcein and observed under a phase contrast microscope Olympus BX40 (Olympus, Tokyo, Japan) using a 20X magnification objective. The general appearance, shape and structure of ovaries were analyzed as previously described $[115,116]$ and, the presence of sperm inside each one of the three spermathecae was visualized as previously described [112]. Sperm presence was determined whenever we visualized conspicuous bundles of sperm. For each female, the content of each spermatheca (presence/absence of sperm) was recorded.

\section{Results}

Molecular characterization of Wolbachia

Wolbachia was positively detected in all the $A$. fraterculus adults tested ( $N=76$; Table 1$)$ using the $16 S r R N A$ and wsp gene PCR-based assays. $16 S r R N A$ sequence analysis showed identical base composition among samples (76 DNA samples, 380 bases). Basic Local Alignment Search Tool (BLAST) searches against the European Nucleotide Archive (ENA, EMBL, EBI) showed 100\% identity with a large number of sequences including wMel (Wolbachia endosymbiont of Drosophila melanogaster; GenBank accession DQ412083.1).

In the case of wsp gene sequences (507 bases) a unique non-synonymous nucleotide change $(\mathrm{C} / \mathrm{T})$ was detected among the 76 samples analyzed (Fig. 1). The wsp nucleotide variants detected were named $w$ AfraCast1_A and $w$ AfraCast2_A respectively. BLAST nucleotide search of $w s p$ gene sequence from $w$ AfraCast1_A showed $100 \%$ identity with $A$. fraterculus isolate wAfBrazil_A (EU651897.1) and A. fraterculus isolate wAfPeru_A (EU651893.1) among others. The wsp nucleotide sequence of wAfraCast2_A showed 100\% identity only with $A$. fraterculus isolate wAfArgentina_A (EU651896.1).

The analysis of the HVRs of the wsp gene performed through the Wolbachia MLST webpage, evidenced different wsp allele and allelic profiles in HVR4 for the Wolbachia nucleotide variants identified here (Table 3). Further HVRs allelic profiles comparison revealed perfect match between wAfraCast1_A and several Wolbachia strains including Wolbachia strains infecting Rhagoletis cerasi (Diptera: Tephritidae) and Leucophenga maculosa (Diptera: Drosophilidae), whereas $w$ AfraCast2_A showed no perfect match in this database.

MLST analysis showed identical nucleotide sequences in 22 DNA samples from the different $A$. fraterculus populations evaluated (Table 1). The MLST allelic profile obtained corresponds to gatB:1, coxA:1, hcpA:1, ftsZ: 3 and $f b p A: 1$ and sequence type (ST) 13. Phylogenetic analysis based on a concatenated dataset of 5 MLST loci (2079 bases) including the nucleotide sequences obtained here and a dataset of representative sequences from A, B and D Wolbachia supergroups from Baldo and Werren [103] revealed that Wolbachia found in Argentinean A. fraterculus populations belong to supergroup A (Fig. 2).

In addition to MLST analysis, we evaluated the polymorphisms in seven additional loci from the Wolbachia genome ( $g r o \mathrm{EL}, g l t \mathrm{~A}, d n a \mathrm{~A}, s u c \mathrm{~B}, a s p \mathrm{C}, a t p \mathrm{D}$ and $p d h \mathrm{~B}$ ) in at least three individuals of Af-Cast-1 and Af-Cast-2 strains. After the analysis of at least $370 \mathrm{~b}$ from each locus (see details in Table 2) no polymorphism was identified showing a high similarity between wAfraCast1_A and wAfraCast2_A at genomic level (see sequence alignments in Additional file 2). The sequence comparisons using BLAST also evidenced similarities among sequences from Wolbachia infecting Drosophila species

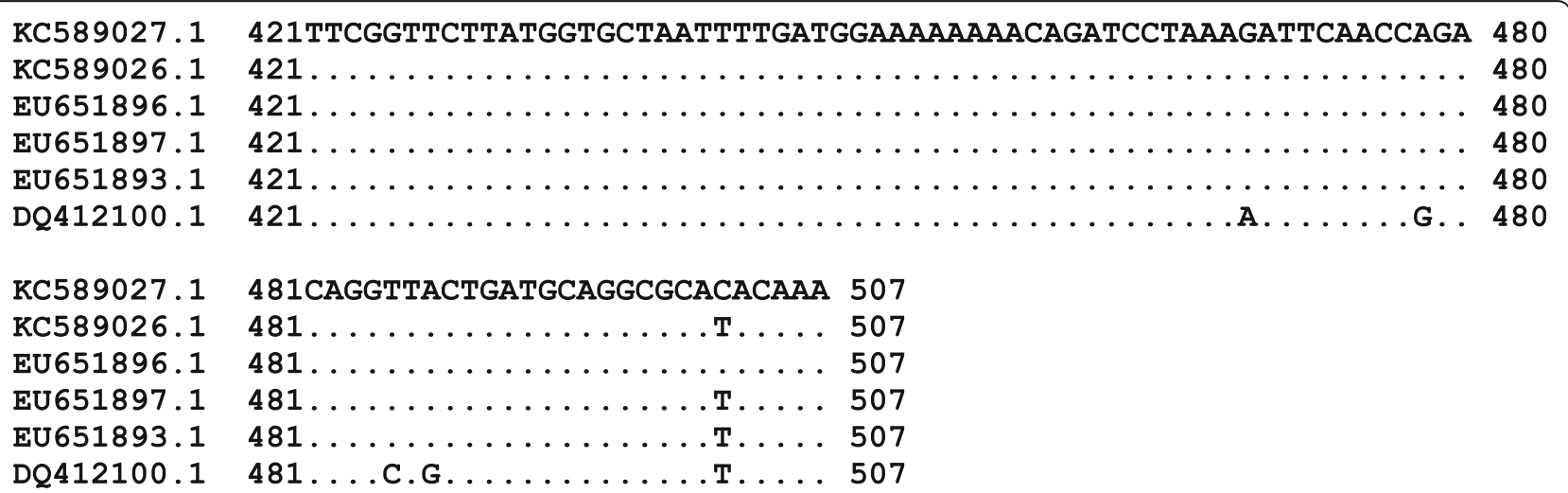

Fig. 1 Identification of the single nucleotide substitution in $507 \mathrm{bp}$ alignment of Wolbachia wsp sequences. The figure shows a section of the wsp nucleotide sequences alignment including Wolbachia sequences described here (AN KC589026.1 and KC589027.1 GenBank) corresponding to wAfraCast1_A or wAfraCast2_A respectively and, sequences from GenBank (NCBI) corresponding to the A. fraterculus isolate wAfArgentina_A (EU651896.1); A. fraterculus isolate WAfBrazil_A (EU651897.1); A. fraterculus isolate WAfPeru_A (EU651893.1) and Wolbachia strain wMel infecting D. melanogaster (DQ412100.1) 
Table 3 Characterization of the wsp HVRs. HVR allele definition is based on the amino acid motifs analysis of the wsp gene sequence (61-573 bp) in respect of wMel (Wolbachia databases - webpage pubmlst.org/Wolbachia/). Assigned alleles to wsp nucleotide sequences are also showed (wsp allele)

\begin{tabular}{llllll}
\hline Wolbachia strain ID & HVR1 & HVR2 & HVR3 & HVR4 & wsp allele \\
\hline wAfraCast1_A & 1 & 12 & 21 & 19 & 23 \\
wAfraCast2_A & 1 & 12 & 21 & 283 & 663 \\
\hline
\end{tabular}

( $w \mathrm{Mel}, w \mathrm{Ri}, w \mathrm{Ha}$ ) for the five genes evaluated, confirming the results obtained by MLST and phylogenetic analyses of $w$ AfraCast $1 / 2 \_\mathrm{A}$ clustered with $w \mathrm{Mel}$ group from supergroup A (Fig. 2).

\section{Prevalence of Wolbachia}

Wolbachia was detected in $100 \%$ of A. fraterculus individuals through PCR amplification and sequencing of wsp and $16 S$ rRNA genes. A different prevalence of the two Wolbachia sequence variants identified in $A$. fraterculus populations was observed (Table 4). We found $w$ AfraCast1_A in $16 \%$ and $w$ AfraCast2_A in $84 \%$ of the $A$. fraterculus individuals from our laboratory colony (37 individuals; 24 females, 13 males). In addition, we identified $w$ AfraCast2_A in $95 \%$ of the insects from natural populations (39 individuals; 22 females, 17 males) while only two individuals from Puerto Yeruá (Entre Rios) showed the presence of wAfraCast1_A (Table 4). Based on PCR and direct sequencing, no evidence of double infections was detected in the 76 A. fraterculus DNA samples analyzed.

\section{Cytoplasmic Wolbachia in A. fraterculus}

The presence of cytoplasmic Wolbachia and the lack of obvious Wolbachia integrations into the host genome (at least detectable with the molecular methods used in the present study) were confirmed in both $A$. fraterculus strains (Af-Cast-1 and Af-Cast-2) by means of antibiotic treatment followed by PCR assays. Wolbachia was not detected in any of the individuals treated with antibiotic

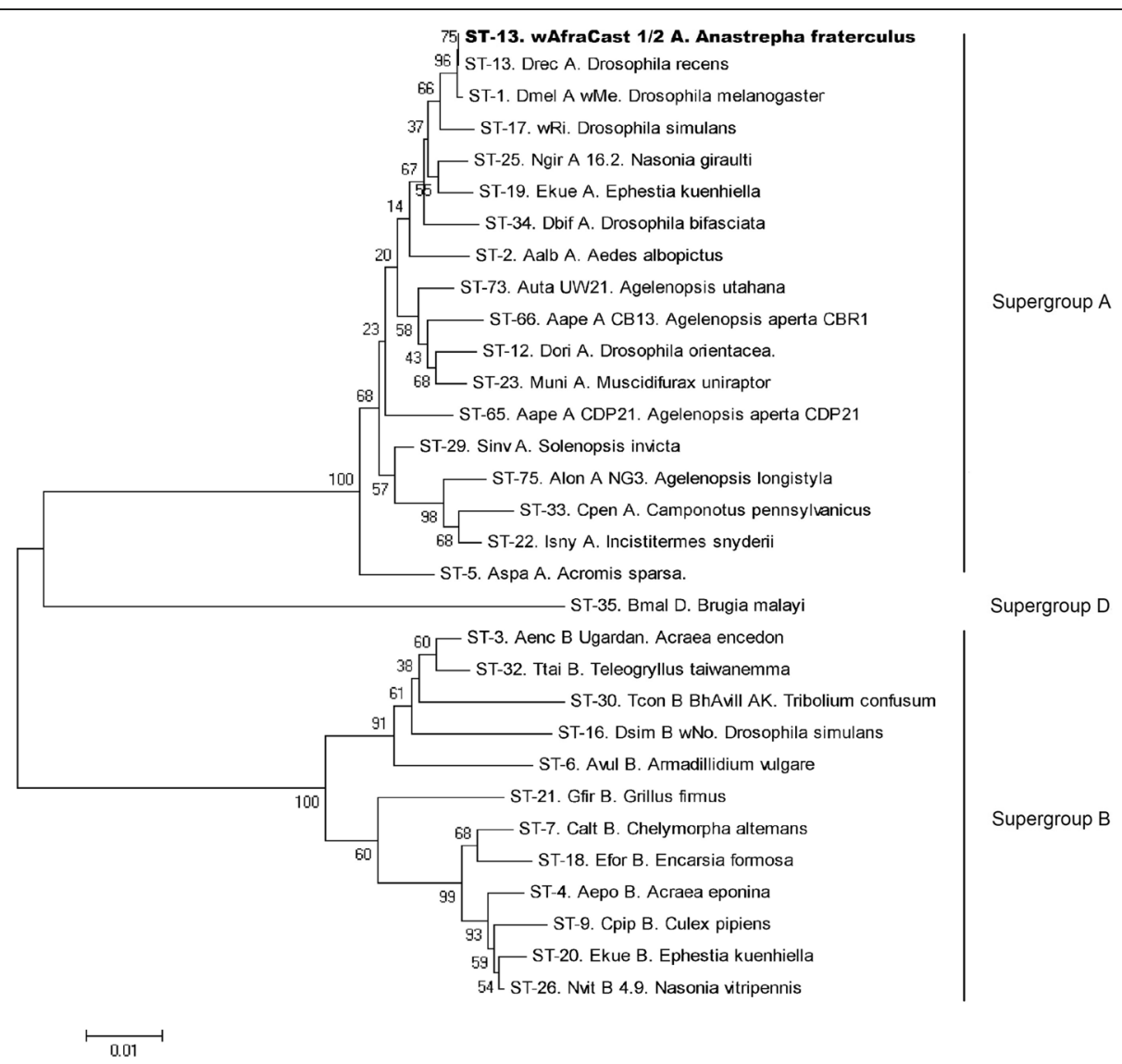

Fig. 2 Neighbor-joining tree reconstructed based on concatenated MLST data (2079 bases). Phylogenetic tree reconstructed using a dataset including 30 MLST concatenated sequences published by Baldo and Werren [103] and a unique sequence corresponding to the concatenated MLST from wAfraCast1/2_A. Branch name is identified as Wolbachia sequence type (ST)- Wolbachia strain (if known)- host species name. Numbers in nodes indicate bootstrap support percentage (1000 replicates). Wolbachia supergroups are shown to the right of the tree. Similar topology was observed using Maximum Likelihood analysis (Additional file 4) 
Table 4 Prevalence of Wolbachia in A. fraterculus from Argentina

\begin{tabular}{llll}
\hline Population ID & wAfraCast1_A (\%) & WAfraCast2_A (\%) & N \\
\hline Horco Molle (Tucumán) & 0.00 & 100.00 & 14 \\
Villa Zorraquín (Entre Ríos) & 0.00 & 100.00 & 10 \\
Puerto Yeruá (Entre Ríos) & 13.33 & 86.67 & 15 \\
IGEAF strain (Castelar, Buenos Aires) & 16.20 & 83.80 & 37 \\
Total & 10.39 & 89.61 & 76 \\
\hline
\end{tabular}

\%: Percentage of Wolbachia infected individuals; N: number of individuals analyzed

(10 flies), whereas, control individuals (10 flies belonging to Af-Cast-1 and Af-Cast-2 strains reared without antibiotic treatment) resulted in a positive Wolbachia-specific amplicon in $100 \%$ of the cases.

\section{Mating experiments}

We followed the scheme of crossing experiments described in Fig. 3. Parental crosses and filial crosses (sibling matings) were performed to analyze the existence of pre- and post-zygotic sexual isolation barriers associated to Wolbachia. Specific PCR bands of approximately $430 \mathrm{bp}$ corresponding to Wolbachia wsp gene were successfully amplified in all Wolbachia-infected $A$. fraterculus individuals used in the crossing experiments (parental flies, Fig. 3). Additionally, the absence of PCR amplicons was evidenced for all Wolbachia-cured parental pairs used as a control of our experiments.

Pre-zygotic isolation test: We observed similar percentages of mating among the four possible types of cross (Chi-square test: $x^{2}=6.637, P=0.084$, d.f. $=3$ ) with a relatively high mean percentage of mated couples (72\%) compared to previous results for this species. The latency and mating duration time did not differ among the types of crosses [ANOVA: Latency: $F(3,165)=1.831$, $P=0.143$; Mating duration time: $F(3,165)=2.597$,

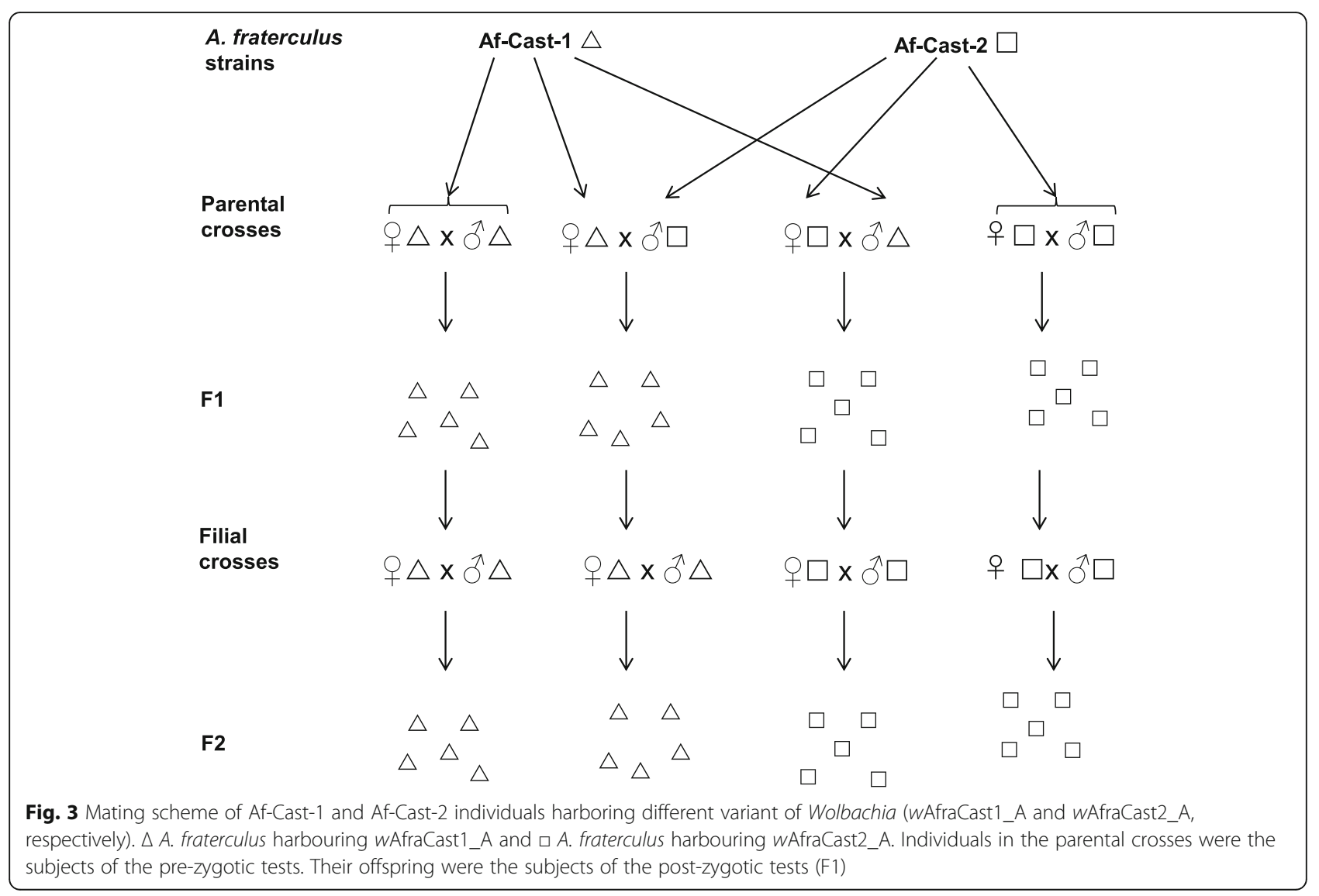


Table 5 Mean values of percentage of mating, latency, and mating duration time of each type of cross, and female proportion obtained in the offspring (F1 and F2)

\begin{tabular}{|c|c|c|c|c|c|}
\hline \multirow{2}{*}{$\begin{array}{l}\text { Mating combination } \\
\text { (female } x \text { male) }\end{array}$} & \multirow{2}{*}{$\begin{array}{l}\text { \% Mating success } \\
\text { (\# rep.) }\end{array}$} & \multirow[t]{2}{*}{ Latency (min) (SE) } & \multirow[t]{2}{*}{ Mating duration time (min) (SE) } & \multicolumn{2}{|c|}{ Offspring female ratio (N) } \\
\hline & & & & $\overline{F 1}$ & F2 \\
\hline Af-Cast-1 $\times$ Af-Cast-1 & $68.5(54)$ & $22.78(2.53) \mathrm{a}$ & $67.50(4.93) \mathrm{a}$ & $0.55 a(506)$ & $0.58 a^{*}(429)$ \\
\hline Af-Cast-1 $\times$ Af-Cast-2 & $80(60)$ & $19.23(2.51) \mathrm{a}$ & $73.60(3.90) \mathrm{a}$ & $0.62 b^{*}(535)$ & $0.61 b^{*}(326)$ \\
\hline Af-Cast-2 x Af-Cast-2 & $78.5(65)$ & $22.65(3.58) \mathrm{a}$ & $76.54(4.56) \mathrm{a}$ & $0.48 c(1013)$ & 0.47c (164) \\
\hline Af-Cast-2 $\times$ Af-Cast-1 & $61.8(55)$ & $26.88(4.20) \mathrm{a}$ & $59.75(3.91) a$ & $0.47 c(455)$ & $0.52 c(389)$ \\
\hline
\end{tabular}

\# rep: number of replicates; min: minutes; SE: standard error; $\mathrm{N}$ : the number of individuals. Values followed by the same letter did not present any statistically significant differences. Statistical significance in the case of female ratio: ${ }^{*} P<0.05$ (corrected critical value after Bonferroni correction $=0.00625$ )

$P=0.054]$ (Table 5). These results showed a lack of prezygotic isolation between the $A$. fraterculus $s p 1$ strains described here.

\section{Post-zygotic isolation analysis}

We did not observe any statistically significant differences among the types of crosses regarding the percentage of eggs that hatched and adults that emerged in the F1 generation [\%Egg hatch: F $(3,82)=0.52, P=0.67$; \% Adults emergence: $F(3,48)=0.28, P=0.84 \mathrm{l}$. In contrast, the percentage of pupation showed statistically significant differences among crosses [ANOVA: $F(3,46)=4.78, P<0.01$ ] Multiple comparison analysis showed that the Af-Cast- $1 \mathrm{x}$ Af-Cast-1 cross had a statistically significant lower percentage of pupation than the Af-Cast- 2 x Af-Cast- 2 cross. The other two types of crosses (Af-Cast- 1 x Af-Cast- 2 and Af-Cast-2 x Af-Cast-1) showed intermediate pupation values (Fig. 4 A-C).

In the F2 generation, we observed that the percentage of egg hatch and the percentage of pupation showed no statistically significant differences among crosses [F (3, $30)=2.15, p=0.18$; and $\mathrm{F}(3,29)=1.49, p=0.24$, respectively] (Fig. $4 \mathrm{D}$ and $\mathrm{E}$ ). However, the percentage of adult emergence showed statistically significant differences among crosses $(\mathrm{F}(3,28)=3.46 ; p=0.029)$. Furthermore, Af-Cast-1 x Af-Cast-1 families showed the lowest percentages of adult emergence and Af-Cast-2 x Af-Cast-1 families the highest (Tukey test) (Fig. 4 F).

A sex ratio distortion that significantly favored females (both in F1 and F2 offspring) was detected in Af-Cast-1 $\mathrm{x}$ Af-Cast- 2 crosses, whereas, in the case of Af-Cast- $1 \mathrm{x}$ Af-Cast-1 crosses, significant deviation of this parameter was observed only in F2 descendants. No bias was evidenced in crosses involving Af-Cast-2 females (Table 5).

Further analysis of data obtained from the parental crosses gave no statistically significant differences regarding percentage of mated females that produce eggs $\left(\chi^{2}=2.321 ; p=0.508\right.$, d.f. $\left.=3\right)$, percentage of females that produce viable eggs $\left(x^{2}=2.322, p=0.508\right.$, d.f. $\left.=3\right)$, percentage of females with descendants $\left(\chi^{2}=0.396\right.$, $p=0.941$, d.f. $=3$ ), percentage of females that produce viable eggs $\left(\chi^{2}=4.893, p=0.180\right.$, d.f. $\left.=3\right)$ and percentage of females with descendants $\left(\chi^{2}=5.778, p=0.123\right.$, d.f. $=$ 3), (Fig. 5 A-E). Since data were homogeneous, results were pooled and compared between types of female. Again, the percentage of mated females that produced eggs did not differ between type of female $\left(x^{2}=1.956\right.$, $p=0.162$, d.f. $=1$ ) (Fig. 5 F). Similarly, the percentage of females that produce viable eggs and the percentage of females with descendants were not statistically different between types of female $\left(X^{2}=0.632, p=0.427\right.$, d.f. $=1$ and $\chi^{2}=0.070, p=0.791$, d.f. $=1$, respectively) (Fig. $5 \mathrm{G}$ and $\mathrm{H})$. In contrast, both the percentage of mated females that produced viable eggs and the percentage of mated females with descendants were significantly higher for the AfCast- 2 females $\left(\chi^{2}=4.706, p=0.030\right.$, d.f. $=1$; and $\chi^{2}=5$. $560, p=0.018$, d.f. $=1$, respectively) (Fig. $5 \mathrm{I}$ and J).

\section{Cytology of mated females}

For each type of cross, we dissected the ovaries of at least 10 mated females that did not lay eggs and five mated females that laid unviable eggs. In all cases (77 females), we observed ovaries with a normal shape (fully developed and conserved size and structure), similar to the ones observed in reproductively mature females (control females, 15-20 days old) from A. fraterculus IGEAF strain (data not shown). In addition, the cytological analysis of spermathecae showed a high density of sperm (bundles) present in control females (Fig. $6 \mathrm{~A}$ ) and absence of sperm in females that did not lay eggs and females that produced unviable eggs from the crossing experiments (77 females analyzed) (Fig. $6 \mathrm{~B}$ ). It is worth mentioning that $A$. fraterculus is able to lay unfertilized eggs even in the absence of mating (virgin females). The results obtained here highlight the absence of sperm in the spermathecae as the main cause of the lack of descendants in the analyzed crosses.

\section{Detection of other reproductive symbionts}

We evaluated the presence of Spiroplasma sp., Cardinium sp., Rickettsia sp., Arsenophonus sp. and Hamiltonella $s p$. by using specific PCR assays (Table 2). After 
A

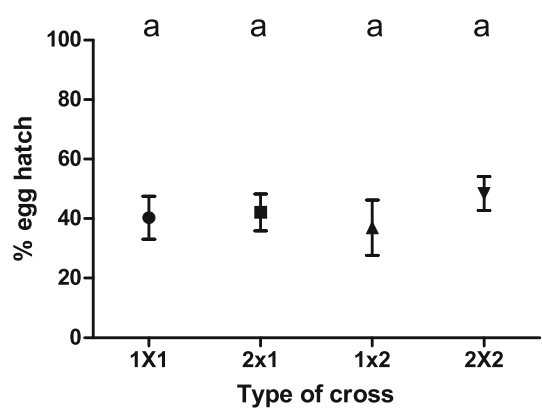

B

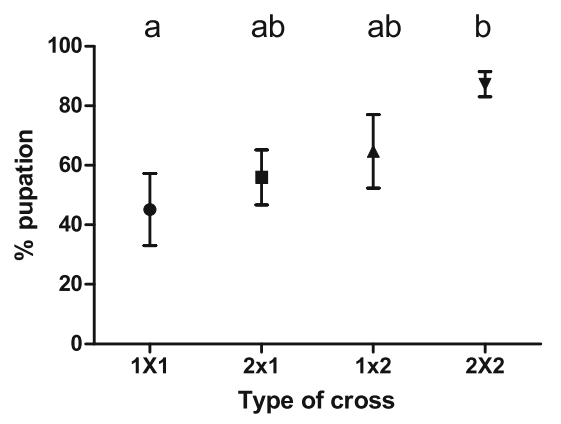

C

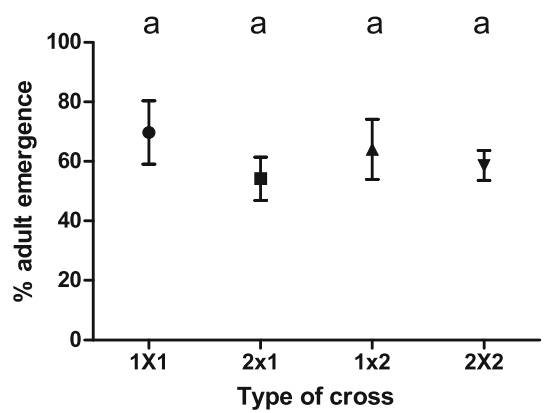

D

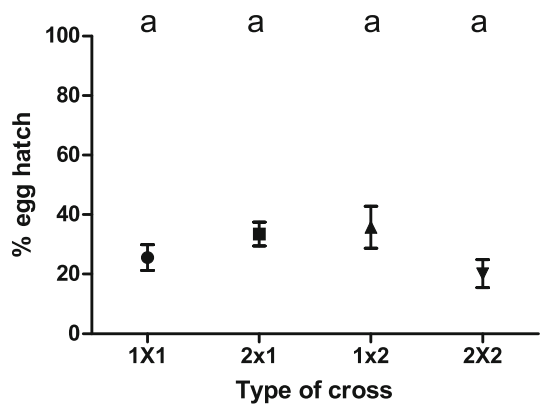

$\mathbf{E}$

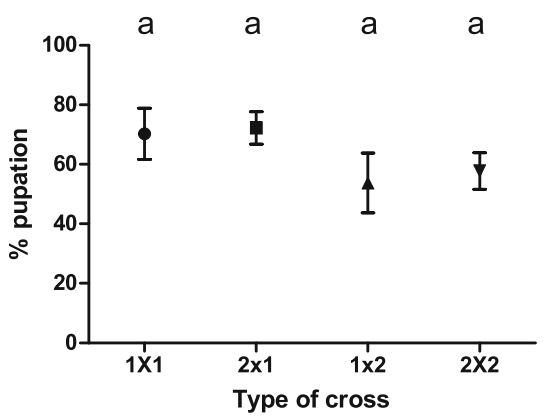

$\mathbf{F}$

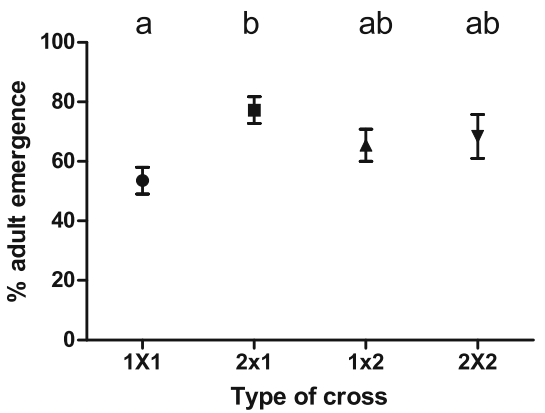

Fig. 4 Survival across development - Parameters measured for each type of cross (female $x$ male). The crosses Af-Cast-1 x Af-Cast-1, Af-Cast- $2 \times$ Af-Cast-1, Af-Cast-1 $\times$ Af-Cast-2, Af-Cast- $2 \times$ Af-Cast- 2 are mentioned in the figure as $1 \times 1,2 \times 1,1 \times 2$ and $2 \times 2$ respectively. a, b and $\mathbf{c}-$ F1 offspring analysis. $\mathbf{d}$, e and $\mathbf{f}-$ F2 offspring analysis. (A/D) mean ( \pm S.E.) \% egg hatch; (B/E) mean ( \pm S.E.) \% pupation= percentage of larvae that reached pupae stage; $(\mathbf{C} / \mathbf{F})$ mean $( \pm$ S.E.) \% adult emergence $=$ percentage of pupae that reached the adult stage. Points sharing a letter did not present any statistically significant differences

the analysis of at least ten DNA samples from each of the $A$. fraterculus IGEAF strains, no symbiont-specific amplicons were obtained.

\section{Discussion}

The presence of Wolbachia in both laboratory and wild A. fraterculus populations from Argentina was evidenced and characterized in this study. Mating experiments showed a slight deficit of males in F1 and F2 progenies and a detrimental effect on larval survival, suggesting that some kind of male-killing phenotype may be associated with the presence of one of the two Wolbachia strains detected in $A$. fraterculus $s p .1$.

The analysis of the wsp gene at a nucleotide level allowed the identification of two sequence variants of Wolbachia in the host populations (named as wAfraCast1_A and wAfraCast2_A). Sequence analysis of concatenated MLST dataset showed that these 
A

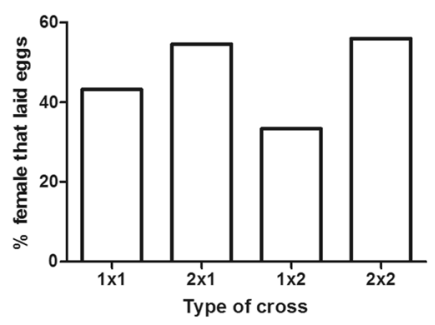

B

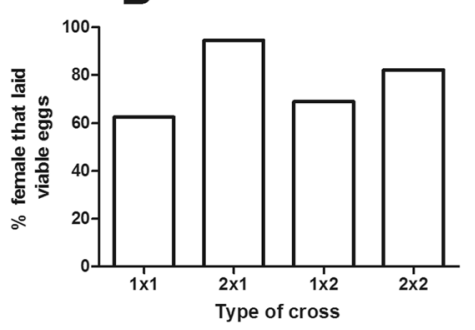

C

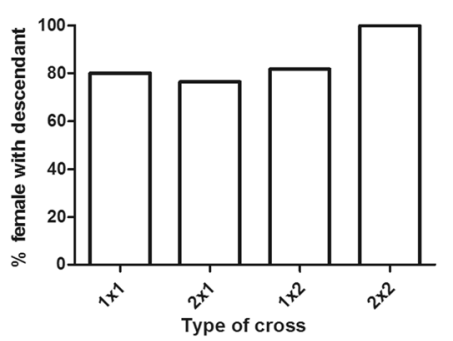

D

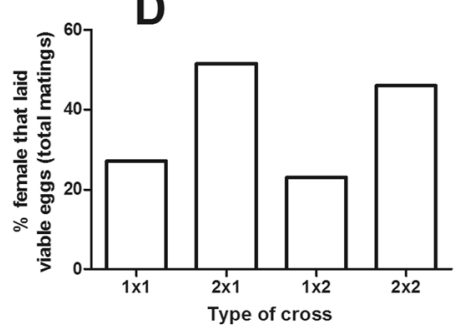

E

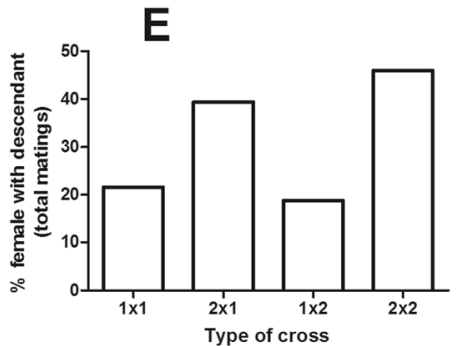

$\mathbf{F}$

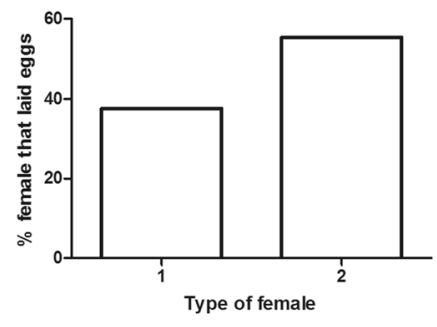

G

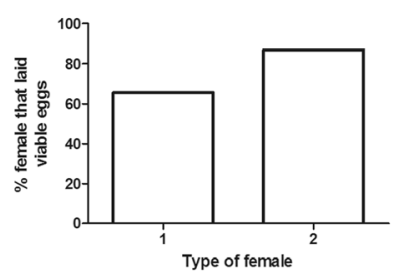

$\mathrm{H}$
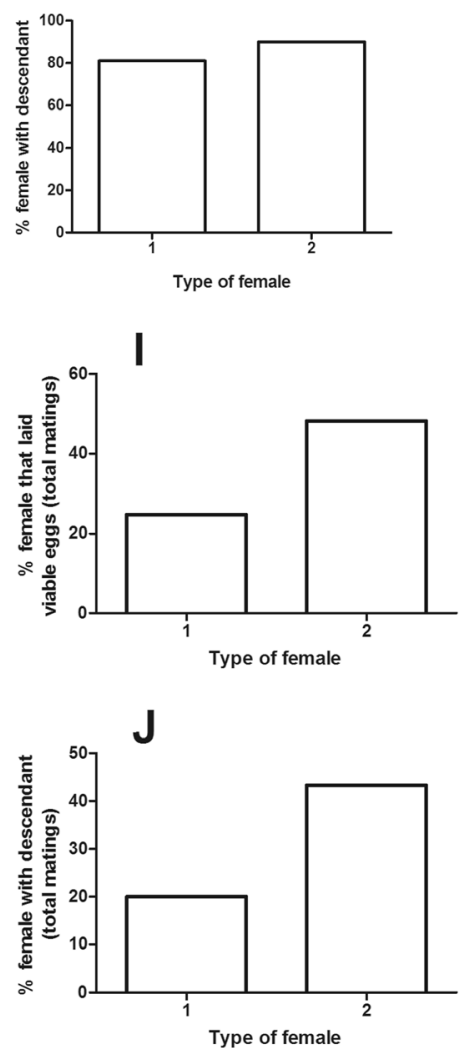

Fig. 5 Mating experiments - additional analyses. a-e represent comparisons that included the four types of crosses. $\mathbf{f - j}$, data coming from the same female were pooled irrespectively of the type of male they mated. Asterisks indicate statistically significant differences ( $p<0.05)$ when percentages were compared by means of a Chi-square test of homogeneity

Wolbachia variants share the same MLST allelic profile. Furthermore, phylogenetic analysis clustered these variants in the same group (ST13) with wMel (Wolbachia infecting D. melanogaster), along with other Wolbachia strains belonging to supergroup A. Our findings using MLST in the identification of Wolbachia (and its clustering in supergroup A) were also supported by $16 \mathrm{~S}$ $r R N A$ sequence analysis. 

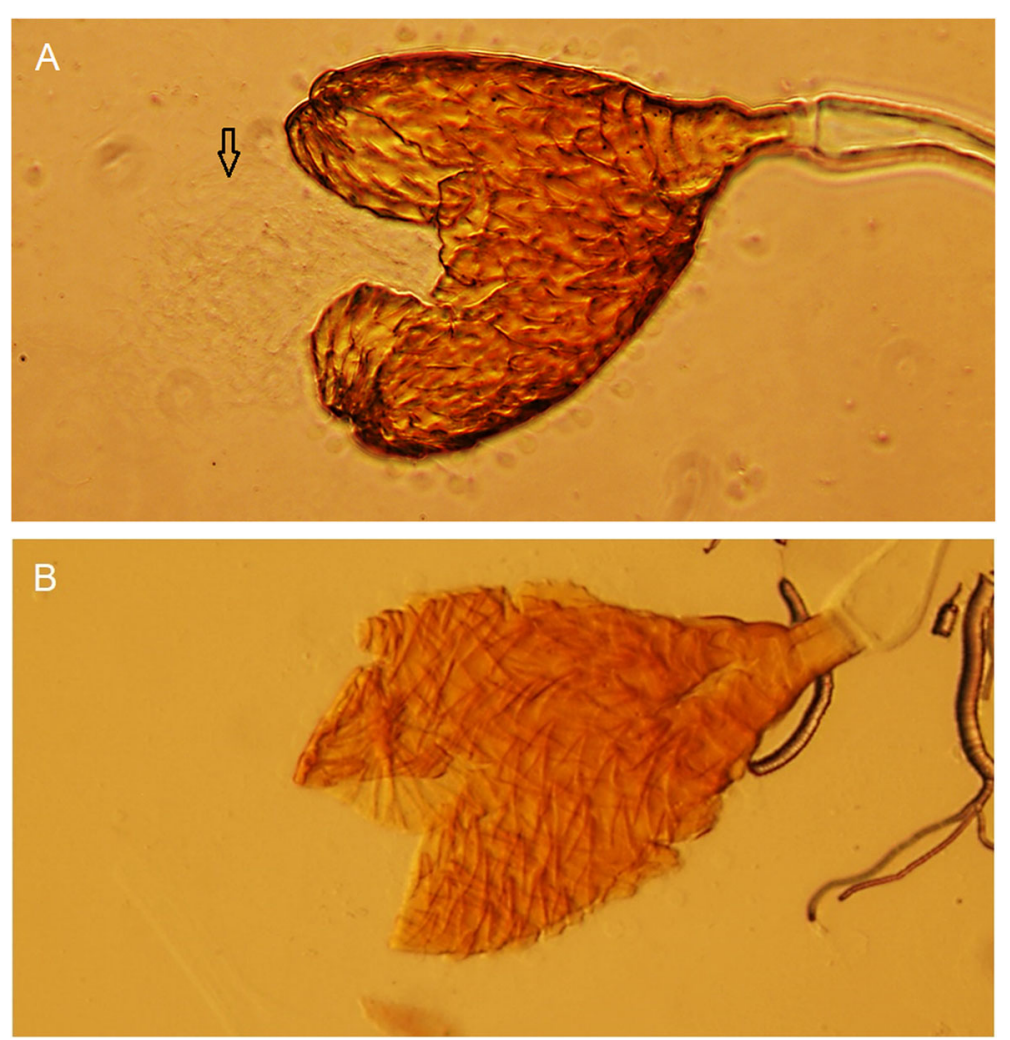

Fig. 6 Cytological analysis of A. fraterculus spermathecae (20X). a: spermatheca of A. fraterculus showing the presence of sperm bundles, which are indicated by an arrow $\mathbf{b}$ spermatheca of $A$. fraterculus showing no sperm in its content

Further characterization of Wolbachia using an antibiotic treatment, allowed the confirmation of an active cytoplasmic infection of this endosymbiont. We did not find evidence of insertion in the A. fraterculus genome, as antibiotic-treated flies showed lack of a specific amplicons for wsp and $16 S$ rRNA Wolbachia genes. In addition, the prevalence analysis of the Wolbachia variants shows the absence of double infections under the experimental design and standard conditions used in the present study. Single infections of Wolbachia have also been described in other A. fraterculus populations [79, 117, 118].

The presence of Wolbachia in Argentinean populations of $A$. fraterculus was first reported by Cáceres et al. [79]. These authors analyzed two laboratory strains of $A$. fraterculus established at Insect Pest Control Laboratory (Seibersdorf, Austria), originally derived from wild flies collected from Argentina and Peru. Each laboratory population harbored closely related Wolbachia strain ( $w$ Arg and $w$ Per, respectively), with the presence of one nucleotide substitution in wArg based on wsp gene sequencing. In the present work, we found identical results at a nucleotide level with these previously reported Wolbachia wsp gene sequences (wAfraCast1_A identical to $w$ Per and $w$ AfraCast2_A identical to $w$ Arg). Moreover, we found that the wAfraCast1_A wsp sequence presented an identical nucleotide composition compared to a partial $w s p$ sequence detected in a Brazilian population of Anastrepha sp.1, (GenBank AN EU 116325) reported by Coscrato and colleagues [117]. The presence of the same wsp gene sequence in different populations of $A$. fraterculus does not necessarily mean that they are infected with identical Wolbachia strains $[16,119]$. The Wolbachia infection status of several morphotypes of the $A$. fraterculus cryptic species complex (including $A$. fraterculus sp.1) was recently published by Prezotto et al. [93]. The information provided by these authors with respect to Wolbachia sequence variants infecting different A. fraterculus populations from Argentina (either using MLST or wsp HVR analyses) differs from our findings. More knowledge regarding the origin of the samples and the number of individuals analyzed by Prezotto et al. [93] are needed in order to compare the results obtained in the two studies. Moreover, the same authors suggested a potential association between specific Wolbachia strains and distinct $A$. fraterculus morphotypes, which could act as a reinforcing factor in the diversification processes, providing also, some evidence of the possible way of transmission of Wolbachia. Further characterization of Wolbachia strains infecting members of the A. fraterculus complex, taking into account crossing experiments and deeper 
molecular analysis could provide insight to the speciation process in this complex, unraveling the genetic entities present and their phylo-geographic distribution.

Our crossing experiments showed a detrimental effect during the development for crosses involving Af-Cast-1 females. This is suggested by a statistically significant lower percentage of pupation in F1 offspring and a lower percentage of adults emergence in F2 descendants observed in the crosses involving Af-Cast-1 flies. Despite the lack of differences between females in the percentage of mated females that laid eggs, those that laid viable eggs, and those that successfully produced progeny, we were able to find a tendency to lower values in Af-Cast1 females, which was statistically significant when these percentages were computed considering the total number of mated females, which allowed these small, nonsignificant effects, to accumulate. These results might point to a negative effect of a Wolbachia variant on the reproductive biology of its host. We also found that some parameters associated to immature development varied in some crosses between F1 and F2. For instance, Af-Cast- 2 x Af-Cast- 2 cross yielded higher egg hatch and pupation in the F1 than in the F2. Because these crosses involved flies with equivalent genetic background and Wolbachia infection status, this result suggests that unidentified experimental conditions probably varied between the F1 and F2.

Cytological analysis showed the absence of sperm in the spermathecae of females that did not lay eggs and females that produced unviable eggs, showing that the lack of sperm transfer is the main cause of unviable embryos production in some families. This result combined with the lack of differences in the \% of hatched eggs allowed us to rule out the presence of a bidirectional cytoplasmic incompatibility associated to Wolbachia infection in the tested crosses. Also, it supports the hypothesis that detrimental effects in the survival associated to Wolbachia would occur later in the developmental stages rising new questions regarding possible effects of this bacterium on the host's reproductive behavior that should be further addressed.

The analysis of sex ratio in each type of cross and generation showed a distortion in favor of females in crosses involving Af-Cast-1 females. Particularly, we observed this type of distortion in F1 and F2 of Af-Cast-1 x AfCast-2 pairs, and F2 offspring from Af-Cast- 1 x Af-Cast1 crosses. Additionally, individual analyses of each family showed that only a few paired-crosses appear to contribute with this sex ratio distortion (Additional file 3).

Our finding indicates that the effect of Wolbachia may not be homogeneous among different individuals belonging to the same host strain and requires further analysis. Studies including the quantification of Wolbachia titers in the parental couples and the measurement of biologically important parameters, in connection with genetic studies of the offspring, including cytological (cytogenetic) analysis will provide more evidence of the phenotype elicited by this endosymbiont in A. fraterculus. In this regard, previous studies described the importance of bacterial densities in the expression of a phenotype and the presence of different Wolbachia densities during host development $[2,36]$ using sensitive tools as the quantitative real time PCR (qPCR) and other methods for the detection of low titer reproductive symbionts [120-124]. Moreover, the action of non-bacterial, maternal-inherited microorganisms [125] must also be taken into account for future studies. Detection of low titer endosymbionts using more sensitive methods and the inclusion of crossing experiments involving antibiotic treatments will contribute to a better understanding of our findings.

Detrimental effects (lower \% of pupation and \% of adult emergence in the F1 and F2, respectively) and the sex ratio distortion observed in crosses involving Af-Cast-1 females, potentially elicited by the presence of Wolbachia and associated to a male killing phenotype, have been previously described in insect species by Hurst et al. [45], Dyer and Jaenike [46] and Kageyama and Traut [126]. A larger set of crossing experiments combined with the analysis of several biologically important parameters from the host populations (e.g. fecundity, \% egg hatch, and/or differences in larval and/or pupal survival) are needed to better understand the effects Wolbachia may be inducing to this host species.

The results obtained here display the differences between the phenotype elicited by two Wolbachia sequence variants on their hosts, revealing some disparity in the cross-talk involving the bacteria and its hosts. This may include genetic variability in the bacterium as well as in the host species. In our study, we evidenced a significant similarity between the two Wolbachia strains analyzed, based on the identical MLST allelic profile and the identical sequences of $16 S$ rRNA gene and seven additional Wolbachia genes (groEL, glt $\mathrm{A}, d n a \mathrm{~A}, \operatorname{suc} \mathrm{B}$, $a s p \mathrm{C}, a t p \mathrm{D}$ and $p d h \mathrm{~B})$. It is also worth noting that several studies have demonstrated the importance of the host genetic background associated to the molecular mechanisms involved in the phenotype induced by $\mathrm{Wol}$ bachia [39, 58, 118, 127]. Microsatellite analyses have shown a high genetic variability and differentiation among Argentinean populations of A. fraterculus [90, $128,129]$. Genetic evaluations using this kind of markers could be potentially useful to identify variation between the A. fraterculus strains harboring different Wolbachia variants under study in the present work. These studies may contribute to our understanding of the different reproductive effects displayed by Wolbachia in these singly-infected A. fraterculus strains. 


\section{Conclusion}

This work contributes to the characterization of Wolbachia infection in A. fraterculus sp.1 from Argentina. We gained a first insight on possible mechanisms associated to the Wolbachia - A. fraterculus interaction by crossing singly-infected $A$. fraterculus strains. We found a potential deleterious effect on immature stages and a sex ratio distortion (male-killing) associated to one of the detected Wolbachia variants (wAfraCast1_A). Further mating experiments, coupled with quantification of Wolbachia titers and including cured lines, will shed light on the phenotype elicited by Wolbachia in A. fraterculus. Our findings are important for the characterization of $A$. fraterculus populations from Argentina, and as a contribution to develop environmentally-friendly and species-specific control strategies against this pest.

\section{Supplementary information}

Supplementary information accompanies this paper at https://doi.org/10. 1186/s12866-019-1652-y.

Additional file 1. Symbiont bacteria associated to a male-killing phenotype in arthropods.

Additional file 2. Nucleotide sequences alignments of Wolbachia genes. Comparison between the partial sequences obtained here (consensus sequences between WAfraCast1_A and WAfraCast2_A) with the most similar sequences from GenBank (NBCI).The genes analyzed are: dnaA (378 bases); aspC (818 b); atpD (881 b); groE (846 b); pdhB (642 b); sucB (612 b) and gltA (554 b).

Additional file 3. Sex ratio analysis of families from each type of cross.

Additional file 4. Molecular Phylogenetic analysis based on

concatenated MLST data (2079 bases) by Maximum Likelihood method (Mega5) following the parameters described by Baldo et al. [15].

\section{Abbreviations \\ (NCBI)U.S.: National Library of Medicine, USA.; ANOVA: Analysis of Variance; BLAST: Basic Local Alignment Search Tool, National Center for Biotechnology Information; Bp: Base pairs; Cl: Cytoplasmic Incompatibility; \\ DNA: Deoxyribonucleic Acid; HVR: Hyper Variable Region; IGEAF: Instituto de Genetica "Ewald A. Favret"; IIT: Incompatible Insect Technique; INTA: Instituto Nacional de Tecnología Agropecuaria; MK: Male-Killing; MLST: Multi Locus Sequence Typing; PCR: Polymerase Chain Reaction; SIT: Sterile Insect Technique; TE: Tris base-EDTA(Ethylenediamine tetraacetic acid) solution}

\section{Acknowledgements}

Authors are grateful to María Teresa Vera (University of Tucumán, Argentina) and Juan Pedro Bouvet (INTA Concordia) for their invaluable help in the sampling of infested fruits. Also authors are indebted to Carlos Cáceres and the IPLC Seibersdorf staff (FAO/IAEA, Vienna, Austria) for their assistance in an important part of the activities of this project. We thank the anonymous reviewers for their constructive comments, which helped us to improve the manuscript.

\section{About this supplement}

This article has been published as part of BMC Microbiology Volume 19 Supplement 1, 2019: Proceedings of an FAO/IAEA Coordinated Research Project on Use of Symbiotic Bacteria to Reduce Mass-rearing Costs and Increase Mating Success in Selected Fruit Pests in Support of SIT Application: microbiology. The full contents of the supplement are available online at https:// bmcmicrobiol.biomedcentral.com/articles/supplements/volume-19supplement-1.

\section{Authors' contributions}

CAC and FHM maintained the insects and conducted experimental assays. SBL, DFS, KB and JLC conceived the study. CAC and AAA performed symbiont's identification. CAC performed all molecular assays and analysis. CAC, SBL, FHM and DFS conducted mating assays. SBL, DFS, KB and JLC conducted the data analysis, and wrote the manuscript. All authors read and approved the final manuscript.

\section{Funding}

This work was supported by funds from the National Institute of Agricultural Technology (INTA) through the projects PNBIO 11031023 and AEBIO-242411 (module pests) to SBL; the International Atomic Energy Agency through the Research Contract N¹7041 to DFS and the Agencia Nacional de Promoción Científica y Tecnológica (Argentina) through the project Foncyt-PICT 20130054 to DFS. CAC was supported by the Post-grade and Retraining Program from INTA (2014).

\section{Availability of data and materials}

Wsp gene sequences generated in this study from WAfraCast1_A and wAfraCast2_A have been deposited in the Wolbachia MLST (pubmlst.org/ Wolbachia/) and GenBank, National Center for Biotechnology Information. (NCBI) databases under accession numbers KC589026.1 and KC589027.1. Allelic profile of MLST scheme of five genes (gatB, coxA, hcpA, fbpA and fts Z) from WAfraCast1/2_A and, HVRs allelic profile of wAfraCast1_A and wAfraCast2_A are available on Wolbachia MLST database. Nucleotide sequences of the groEL, gltA, dnaA, sucB, aspC, atpD and $p d h \mathrm{~B}$ genes from Wolbachia infecting Argentinean A. fraterculus were submitted to GenBank (https://www.ncbi.nlm.nih.gov/genbank/index.html) under accession numbers MG977022-28 respectively.

Raw data obtained in this work is available upon request to the corresponding author.

Ethics approval and consent to participate

Each author informed the consent to participate of this publication. All the procedures and methods have been performed in accordance with local laws and regulations.

\section{Consent for publication}

Not applicable.

\section{Competing interests}

The authors declare that they have no competing interests.

\section{Author details}

${ }^{1}$ Laboratorio de Insectos de Importancia Agronómica, IGEAF, Instituto nacional de Tecnología Agropecuaria (INTA) gv IABIMO-CONICET, Hurlingham, Buenos Aires, Argentina. ${ }^{2}$ Consejo Nacional de Investigaciones Científicas y Técnicas, (CONICET), Ministerio de Ciencia, Tecnología e Innovación Productiva (MINCyT), Buenos Aires, Argentina. ${ }^{3}$ Insect Pest Control Laboratory, Joint FAO/IAEA Division of Nuclear Techniques in Food and Agriculture, Vienna, Austria.

Published: 24 December 2019

\section{References}

1. Werren JH. Biology of Wolbachia. Annu Rev Entomol. 1997;42:587-609.

2. Saridaki A, Bourtzis K. Wolbachia: more than just a bug in insects genitals. Curr Opin Microbiol. 2010;13:67-72

3. Glowska E, Dragun-Damian A, Dabert M, Gerth M. New Wolbachia supergroups detected in quill mites (Acari: Syringophilidae). Infect Genet Evol. 2015;30:140-6.

4. Ramírez-Puebla ST, Servín-Garcidueñas LE, Ormeño-Orrillo E, de León AVP Rosenblueth M, Delaye L, et al. Species in Wolbachia? Proposal for the designation of 'Candidatus Wolbachia bourtzisii', 'Candidatus Wolbachia onchocercicola', 'Candidatus Wolbachia blaxteri', 'Candidatus Wolbachia brugii', 'Candidatus Wolbachia taylori', 'Candidatus Wolbachia collembolicola' and 'Candidatus Wolbachia multihospitum' for the different species within Wolbachia supergroups. Syst Appl Microbiol. 2015;38:390-399.

5. Ramírez-Puebla ST, Servín-Garcidueñas LE, Ormeño-Orrillo E, de León AVP, Rosenblueth M, Delaye L, et al. A response to Lindsey et al. Wolbachia 
pipientis should not be split into multiple species: a response to RamírezPuebla et al. Syst Appl Microbiol. 2016;39:223-5.

6. Lindsey ARI, Bordenstein SR, Newton ILG, Rasgon JL. Wolbachia pipientis should not be split into multiple species: a response to Ramírez-Puebla et al., "species in Wolbachia? Proposal for the designation of 'Candidatus Wolbachia bourtzisii', 'Candidatus Wolbachia onchocercicola', Candidatus Wolbachia blax". Syst Appl Microbiol. 2016;39:220-2.

7. Werren JH, Windsor D, Guo L. Distribution of Wolbachia among neotropical arthropods. Proc R Soc Lond B Biol Sci. 1995;262:197-204.

8. Taylor MJ, Voronin D, Johnston KL, Ford L. Wolbachia filarial interactions. Cell Microbiol. 2013;15:520-6

9. Vandekerckhove $\Pi$, Watteyne S, Willems A, Swings JG, Mertens J, Gillis M. Phylogenetic analysis of the $16 \mathrm{~S}$ rDNA of the cytoplasmic bacterium Wolbachia from the novel host Folsomia candida (Hexapoda, Collembola) and its implications for Wolbachia taxonomy. FEMS Microbiol Lett. 1999;180:279-86.

10. Lo N, Casiraghi M, Salati E, Bazzocchi C, Bandi C. How many Wolbachia supergroups exist? Mol Biol Evol. 2002;19:341-6.

11. Rasgon JL, Scott TW. Impact of population age structure on Wolbachia transgene driver efficacy: ecologically complex factors and release of genetically modified mosquitoes. Insect Biochem Mol Biol. 2004;34:707-13.

12. O'Neill SL, Giordano R, Colbert AM, Karr TL, Robertson HM. $16 S$ rRNA phylogenetic analysis of the bacterial endosymbionts associated with cytoplasmic incompatibility in insects. Proc Natl Acad Sci USA.1992;9: 2699-2702.

13. Braig HR, Zhou W, Dobson SL, O'Neill SL. Cloning and characterization of a gene encoding the major surface protein of the bacterial endosymbiont Wolbachia pipientis. J Bacteriol. 1998;180:2373-8.

14. Zhou W, Rousset F, O'Neill S. Phylogeny and PCR-based classification of Wolbachia strains using wsp gene sequences. Proc Biol Sci. 1998; 265:509-15.

15. Baldo L, Hotopp JCD, Jolley KA, Bordenstein SR, Biber SA, Choudhury RR, et al. Multilocus sequence typing system for the endosymbiont Wolbachia pipientis. Appl Environ Microbiol. 2006a;72:7098-110.

16. Paraskevopoulos C, Bordenstein SR, Wernegreen JJ, Werren JH, Bourtzis K. Toward a Wolbachia multilocus sequence typing system: discrimination of Wolbachia strains present in Drosophila species. Curr Microbiol. 2006;53:388-95.

17. Casiraghi M, Bordenstein SR, Baldo L, Lo N, Beninati T, Wernegreen JJ, et al. Phylogeny of Wolbachia pipientis based on gltA, groEL and ftsZ gene sequences: clustering of arthropod and nematode symbionts in the $F$ supergroup, and evidence for further diversity in the Wolbachia tree. Microbiol. 2005;151:4015-22.

18. Augustinos AA, Santos-Garcia D, Dionyssopoulou E, Moreira M, Papapanagiotou A, Scarvelakis M, et al. Detection and characterization of Wolbachia infections in natural populations of aphids: is the hidden diversity fully unraveled? PLoS One. 2011;6:e28695.

19. Bing XL, Xia WQ, Gui JD, Yan GH, Wang XW, Liu SS. Diversity and evolution of the Wolbachia endosymbionts of Bemisia (Hemiptera: Aleyrodidae) whiteflies. Ecol Evol. 2014;4:2714-37.

20. Konecka E, Olszanowski Z. A screen of maternally inherited microbial endosymbionts in oribatid mites (Acari: Oribatida). Microbiol. 2015;161: 1561-71.

21. Dobson SL, Bourtzis K, Braig HR, Jones BF, Zhou W, Rousset F, et al. Wolbachia infections are distributed throughout insect somatic and germ line tissues. Insect Biochem Mol Biol. 1999;29:153-60.

22. Albertson R, Tan V, Leads RR, Reyes M, Sullivan W, Lindley C. Mapping Wolbachia distributions in the adult Drosophila brain. Cell Microbiol. 2013;15: 1527-44.

23. Bandi C, Anderson TJ, Genchi C, Blaxter ML. Phylogeny of Wolbachia in filarial nematodes. Proc R Soc Lond B Biol Sci. 1998;265:2407-13.

24. Taylor MJ, Bandi C, Hoerauf A. Wolbachia. Bacterial endosymbionts of filarial nematodes. Adv Parasitol. 2005;60:245-84.

25. Cheng Q, Ruel TD, Zhou W, Moloo SK, Majiwa P, O'neill SL, et al. Tissue distribution and prevalence of Wolbachia infections in tsetse flies. Glossina spp Med Vet Entomol. 2000;14:44-50.

26. McGraw EA, O'Neill SL. Wolbachia pipientis: intracellular infection and pathogenesis in Drosophila. Curr Opin Microbiol. 2004;7:67-70.

27. Ruang-Areerate T, Kittyapong P, Baimai V, O'Neill SL. Molecular phylogeny of Wolbachia endosymbionts in southeast Asian mosquitoes (Diptera: Culicidae) based on wsp gene sequences. J Med Entomol. 2003;40:1-5.
28. Brelsfoard CL, Dobson SL. Wolbachia-based strategies to control insect pests and disease vectors. Asia Pac J Mol Biol Biotechnol. 2009;17:55-63.

29. Turelli M, Hoffmann AA. Cytoplasmic incompatibility in Drosophila simulans: dynamics and parameter estimates from natural populations. Genetics. 1995;140:1319-38.

30. Dobson SL, Fox CW, Jiggins FM. The effect of Wolbachia-induced cytoplasmic incompatibility on host population size in natural and manipulated systems. P R Soc Lond B Biol Sci. 2002a;269:437-45.

31. Dobson SL, Marsland EJ, Rattanadechakul W. Mutualistic Wolbachia infection in Aedes albopictus: accelerating cytoplasmic drive. Genetics. 2002b;160:1087-94.

32. Dobson SL. Reversing Wolbachia-based population replacement. Trends Parasitol. 2003;19:128-33.

33. Xi Z, Khoo CC, Dobson SL. Wolbachia establishment and invasion in an Aedes aegypti laboratory population. Science. 2005;310:326-8.

34. Bourtzis K, O'neill SL. Wolbachia infections and arthropod reproduction. Bioscience. 1998:48:287-93.

35. Stouthamer R, Breeuwer JA, Hurst GD. Wolbachia pipientis: microbial manipulator of arthropod reproduction. Annu Rev Microbiol. 1999;53: $71-102$.

36. Werren JH, Baldo L, Clark ME. Wolbachia: master manipulators of invertebrate biology. Nat Rev Microbiol. 2008;6:741-51.

37. O'Neill SL, Karr TL. Bidirectional incompatibility between conspecific populations of Drosophila simulans. Nature. 1990;348:178-80.

38. Bourtzis K, Braig HR, Karr TL. Cytoplasmic Incompatibility. In: Insect symbiosis vol. 1. K. Bourtzis and T.A. Miller, editors. Boca Raton: CRC Press; 2003. p. 217-246.

39. Zabalou S, Apostolaki A, Pattas S, Veneti Z, Paraskevopoulos C, Livadaras I, et al. Multiple rescue factors within a Wolbachia strain. Genetics. 2008;178: 2145-60.

40. Stouthamer R, Breeuwert JA, Luck RF, Werren JH. Molecular identification of microorganisms associated with parthenogenesis. Nature. 1993;361:6407-66.

41. Pannebakker BA, Pijnacker LP, Zwaan BJ, Beukeboom LW. Cytology of Wolbachia-induced parthenogenesis in Leptopilina clavipes (hymenoptera: Figitidae). Genome. 2004;47:299-303.

42. Rousset F, Bouchon D, Pintureau B, Juchault P, Solignac M. Wolbachia endosymbionts responsible for various alterations of sexuality in arthropods. Proc R Soc Lond B Biol Sci. 1992;250:91-8.

43. Kageyama D, Hoshizaki S, Ishikawa Y. Female-biased sex ratio in the Asian corn borer, Ostrinia furnacalis: evidence for the occurrence of feminizing bacteria in an insect. Heredity. 1998;81:311-6.

44. Bouchon D, Cordaux R, Greve P. Feminizing Wolbachia and the evolution of sex determination in isopods. In: Insect symbiosis vol. 3. K Bourtzis and TA Miller, editors. Boca Ratón: CRC Press; 2008. p.273-294.

45. Hurst GD, Jiggins FM, von der Schulenburg JHG, Bertrand D, West SA, Goriacheva II, et al. Male-killing Wolbachia in two species of insect. Proc R Soc Lond B Biol Sci. 1999;266:735-40.

46. Dyer KA, Jaenike J. Evolutionarily stable infection by a male-killing endosymbiont in Drosophila innubila. Genetics. 2004;168:1443-55.

47. Hurst LD. The evolution of cytoplasmic incompatibility or when spite can be successful. J Theor Biol. 1991;148:269-77.

48. Teixeira L, Ferreira Á, Ashburner M. The bacterial symbiont Wolbachia induces resistance to RNA viral infections in Drosophila melanogaster. PLoS Biol. 2008;6:e1000002.

49. Hedges LM, Brownlie JC, O'neill SL, Johnson KN. Wolbachia and virus protection in insects. Science. 2008:322:702.

50. Kambris Z, Cook PE, Phuc HK, Sinkins SP. Immune activation by lifeshortening Wolbachia and reduced filarial competence in mosquitoes. Science. 2009;326:134-6.

51. Moreira LA, Iturbe-Ormaetxe I, Jeffery JA, Lu G, Pyke AT, Hedges LM, et al. Wolbachia symbiont in Aedes aegypti limits infection with dengue, chikungunya, and Plasmodium. Cell. 2009;139:1268-78.

52. Hughes GL, Koga R, Xue P, Fukatsu T, Rasgon JL. Wolbachia infections are virulent and inhibit the human malaria parasite Plasmodium falciparum in Anopheles gambiae. PLoS Pathog. 2011;7:e1002043.

53. Ye YH, Woolfit M, Rancès E, O'Neill SL, McGraw EA. Wolbachia-associated bacterial protection in the mosquito Aedes aegypti. PLoS Neglect Trop D. 2013;7:e2362. https://doi.org/10.1371/journal.pntd.0002362.

54. Koukou K, Pavlikaki H, Kilias G, Werren JH, Bourtzis K, Alahiotis SN. Influence of antibiotic treatment and Wolbachia curing on sexual isolation among Drosophila melanogaster cage populations. Evolution. 2006;60:87-96. 
55. Miller WJ, Ehrman L, Schneider D. Infectious speciation revisited: impact of symbiont-depletion on female fitness and mating behavior of Drosophila paulistorum. PLoS Pathog. 2010;6:e1001214.

56. Zhao DX, Zhang XF, Chen DS, Zhang YK, Hong XY. Wolbachia-host interactions: host mating patterns affect Wolbachia density dynamics. PLoS One. 2013;8:e66373.

57. Peng Y, Nielsen JE, Cunningham JP, McGraw EA. Wolbachia infection alters olfactory-cued locomotion in Drosophila spp. Appl Environ Microb. 2008;74:3943-8.

58. Zabalou S, Riegler M, Theodorakopoulou M, Stauffer C, Savakis C, Bourtzis K. Wolbachia-induced cytoplasmic incompatibility as a means for insect pest population control. Proc Natl Acad Sci U S A. 2004;101:15042-5.

59. Hoffmann AA, Montgomery BL, Popovici J, Iturbe-Ormaetxe I, Johnson PH, Muzzi F, et al. Successful establishment of Wolbachia in Aedes populations to suppress dengue transmission. Nature. 2011;476:454-7.

60. Bourtzis K, Dobson SL, Xi Z, Rasgon JL, Calvitti M, Moreira LA, et al. Harnessing mosquito-Wolbachia symbiosis for vector and disease control. Acta Trop. 2014;132:S150-63.

61. Bourtzis K, Lees RS, Hendrichs J, Vreysen M. More than one rabbit out of the hat: radiation, transgenic and symbiont-based approaches for sustainable management of mosquito and tsetse fly populations. Acta Trop. 2016;157:115-30.

62. Bourtzis K, Robinson AS. Insect pest control using Wolbachia and/or radiation. In Insect Symbiosis vol. 2. K Bourtzis and TA Miller, editors. Boca Ratón: CRC Press; 2006. p. 225-246.

63. Zabalou S, Apostolaki A, Livadaras I, Franz G, Robinson AS, Savakis C, et al. Incompatible insect technique: incompatible males from a Ceratitis capitata genetic sexing strain. Entomol Exp Appl. 2009;132:232-40.

64. Alam U, Medlock J, Brelsfoard C, Pais R, Lohs C, Balmand S, et al. Wolbachia symbiont infections induce strong cytoplasmic incompatibility in the tsetse fly Glossina morsitans. PLoS Pathog. 2011;7:e1002415.

65. Zhang D, Lees RS, Xi Z, Gilles JR, Bourtzis K. Combining the sterile insect technique with Wolbachia-based approaches: II-a safer approach to Aedes albopictus population suppression programmes, designed to minimize the consequences of inadvertent female release. PLoS One. 2015a;10:e0135194.

66. Zhang D, Zheng X, Xi Z, Bourtzis K, Gilles JR. Combining the sterile insect technique with the incompatible insect technique: I-impact of Wolbachia infection on the fitness of triple-and double-infected strains of Aedes albopictus. PLoS One. 2015b;10:e0121126.

67. Zhang D, Lees RS, Xi Z, Bourtzis K, Gilles JR. Combining the sterile insect technique with the incompatible insect technique: II-robust mating competitiveness of irradiated triple Wolbachia-infected Aedes albopictus males under semi-field conditions. PLoS One. 2016;11:e0151864.

68. Hurst GD, Johnson AP, Schulenburg JH, Fuyama Y. Male-killing Wolbachia in Drosophila: a temperature-sensitive trait with a threshold bacterial density. Genetics. 2000;156:699-709.

69. Berec L, Maxin D, Bernhauerová V. Male killing bacteria as agents of insect pest control. J Appl Ecol. 2016:53:1270-9.

70. White IM, Elson-Harris MM. Fruit flies of economic significance: their identification and bionomics. CAB International. 1992

71. Norrbom AL, Zucchi RA, Hernández-Ortiz V. Phylogeny of the genera Anastrepha and Toxotrypana (Trypetinae: Toxotrypanini) based on morphology. In: Fruit flies (Tephritidae): phylogeny and evolution of behavior. Boca Raton: CRC Press; 1999. p. 299-342.

72. Zucchi RA. Lista das espécies de Anastrepha, sinonímias, plantas hospedeiras e parasitóides. In A. Malavasi \& R.A. Zucchi Editors. Moscas-das-frutas de importância econômica no Brasil. Ribeirão Preto, Holos Eds. 2000. p. 327.

73. Hernández-Ortiz V, Bartolucci AF, Morales-Valles P, Frías D, Selivon D. Cryptic species of the Anastrepha fraterculus complex (Diptera: Tephritidae): a multivariate approach for the recognition of south American morphotypes. Ann Entomol Soc Am. 2012;105:305-18.

74. Steck GJ. Taxonomic status of Anastrepha fraterculus. The south American fruit fly, Anastrepha fraterculus (Wied.); advances in artificial rearing, taxonomic status and biological. IAEA Proceedings. 1999:13-20.

75. Segura DF, Vera MT, Cagnotti CL, Vaccaro N, De Coll O, Ovruski SM, et al. Relative abundance of Ceratitis capitata and Anastrepha fraterculus (Diptera: Tephritidae) in diverse host species and localities of Argentina. Ann Entomol Soc Am. 2006;99:70-83.

76. Cladera JL, Vilardi JC, Juri M, Paulin LE, Giardini MC, Gomez-Cendra PV, et al. Genetics and biology of Anastrepha fraterculus: research supporting the use of the sterile insect technique (SIT) to control this pest in Argentina. BMC Genet. 2014;15:S12.
77. Hernández-Ortiz V, Canal NA, Salas JOT, Ruíz-Hurtado FM, Dzul-Cauich JF. Taxonomy and phenotypic relationships of the Anastrepha fraterculus complex in the Mesoamerican and Pacific Neotropical dominions (Diptera, Tephritidae). ZooKeys. 2015;540:95.

78. Vera MT, Cáceres C, Wornoayporn W, Islam A, Robinson AS, De LA Vega MH, et al. Mating incompatibility among populations of the south American fruit fly Anastrepha fraterculus (Diptera: Tephritidae). Ann Entomol Soc Am. 2006; 99:387-97.

79. Cáceres C, Segura DF, Vera MT, Wornoayporn V, Cladera JL, Teal P, et al. Incipient speciation revealed in Anastrepha fraterculus (Diptera; Tephritidae) by studies on mating compatibility, sex pheromones, hybridization, and cytology. Biol J Linn Soc. 2009;97:152-65.

80. Juárez ML, Devescovi F, Bř́zová R, Bachmann G, Segura DF, Kalinová B, et al. Evaluating mating compatibility within fruit fly cryptic species complexes and the potential role of sex pheromones in pre-mating isolation. ZooKeys. 2015;540:125.

81. Vaníčková L, Hernández-Ortiz V, Bravo ISJ, Dias V, Roriz AKP, Laumann RA, et al. Current knowledge of the species complex Anastrepha fraterculus (Diptera, Tephritidae) in Brazil. Zookeys. 2015;540:211.

82. Selivon D, Perondini ALP, Morgante JS. A genetic-morphological characterization of two cryptic species of the Anastrepha fraterculus complex (Diptera: Tephritidae). Ann Entomol Soc Am. 2005;98:367-81.

83. Goday C, Selivon D, Perondini ALP, Greciano PG, Ruiz MF. Cytological characterization of sex chromosomes and ribosomal DNA location in Anastrepha species (Diptera, Tephritidae). Cytogenet Genome Res. 2006; 114:70-6.

84. Dias VS, Silva JG, Lima KM, Petitinga CS, Hernández-Ortiz V, Laumann RA, et al. An integrative multidisciplinary approach to understanding cryptic divergence in Brazilian species of the Anastrepha fraterculus complex (Diptera: Tephritidae). Biol J Linn Soc. 2016;117:725-46.

85. Manni M, Lima KM, Guglielmino CR, Lanzavecchia SB, Juri M, Vera MT, et al. Relevant genetic differentiation among Brazilian populations of Anastrepha fraterculus (Diptera, Tephritidae). ZooKeys. 2015;540:157-73.

86. Sutton BD, Steck GJ, Norrbom AL, Rodriguez EJ, Srivastava P, Alvarado NN, et al. Nuclear ribosomal internal transcribed spacer 1 (ITS1) variation in the Anastrepha fraterculus cryptic species complex (Diptera, Tephritidae) of the Andean region. ZooKeys. 2015;540:175.

87. Petit-Marty N, Vera MT, Calcagno G, Cladera JL, Vilardi JC. Lack of postmating isolation between two populations of Anastrepha fraterculus from different ecological regions in Argentina. Proceedings of the 6th international symposium on fruit flies of economic importance, Stellenbosch, South Africa, 6-10 May 2002. Isteg Scientific Publications. 2004a;79-82

88. Petit-Marty N, Vera MT, Calcagno G, Cladera JL, Segura DF, Allinghi A, et al. Sexual behavior and mating compatibility among four populations of Anastrepha fraterculus (Diptera: Tephritidae) from Argentina. Ann Entomol Soc Am. 2004b;97:1320-7.

89. Rull J, Abraham S, Kovaleski A, Segura DF, Mendoza M, Liendo M, et al. Evolution of pre-zygotic and post-zygotic barriers to gene flow among three cryptic species within the Anastrepha fraterculus complex. Entomol Exp Appl. 2013;148:213-22.

90. Alberti AC, Confalonieri VA, Zandomeni RO, Vilardi JC. Phylogeographic studies on natural populations of the south American fruit fly, Anastrepha fraterculus (Diptera: Tephritidae). Genetica. 2008;132:1-8.

91. Alberti AC, Rodriguero MS, Cendra PG, Saidman BO, Vilardi JC. Evidence indicating that argentine populations of Anastrepha fraterculus (Diptera: Tephritidae) belong to a single biological species. Ann Entomol Soc Am. 2002;95:505-12.

92. Selivon D, Perondini AP, Ribeiro AF, Marino CL, Lima MM, Coscrato VE. Wolbachia endosymbiont in a species of the Anastrepha fraterculus complex (Diptera: Tephritidae). Invertebr Reprod Dev. 2002;42:121-7.

93. Prezotto LF, Perondini AL, Hernández-Ortiz V, Marino CL, Selivon D. Wolbachia strains in cryptic species of the Anastrepha fraterculus complex (Diptera, Tephritidae) along the Neotropical region. Syst Appl Microbiol. 2017:40:59-67.

94. Vera T, Abraham S, Oviedo A, Willink E. Demographic and quality control parameters of Anastrepha fraterculus (Diptera: Tephritidae) maintained under artificial rearing. Fla Entomol. 2007:90:53-7.

95. Jaldo HE, Willink E, Liedo P. Análisis demográfico de la cría masiva de Anastrepha fraterculus (Diptera: Tephritidae) en Tucumán. Argentina Rev Ind Agric Tucumán. 2007;84:15-20. 
96. Jaldo HE, Gramajo MC, Willink E. Mass rearing of Anastrepha fraterculus (Diptera: Tephritidae): a preliminary strategy. Fla Entomol. 2001;84:716-8.

97. Baruffi L, Damiani G, Guglielmino CR, Bandi C, Malacrida AR, Gasperi G. Polymorphism within and between populations of Ceratitis capitata: comparison between RAPD and multilocus enzyme electrophoresis data. Heredity. 1995;74:425-37.

98. Sambrook J, Fritsch E, Maniatis T. Molecular cloning: a laboratory manual. Cold Spring Harbor: Cold Spring Harbor Laboratory Press; 1989. p. 1546.

99. Werren JH, Windsor DM. Wolbachia infection frequencies in insects: evidence of a global equilibrium? Proc R Soc Lond B Biol Sci. 2000; 267(1450):1277-85

100. Baldo L, Lo N, Werren JH. Mosaic nature of wsp (Wolbachia surface protein). J Bacteriol. 2005;187:5406-18.

101. Hall TA. BioEdit: a user-friendly biological sequence alignment editor and analysis program for windows 95/98/NT. Nucl Acids Symp Ser. 1999;41:95-8.

102. Staden R. The Staden sequence analysis package. Mol Biotechnol. 1996; $5: 233-41$.

103. Baldo L, Werren JH. Revisiting Wolbachia supergroup typing based on WSP: spurious lineages and discordance with MLST. Curr Microbiol. 2007:55:81-7.

104. Tamura K, Peterson D, Peterson N, Stecher G, Nei M, Kumar S. MEGA5: molecular evolutionary genetics analysis using maximum likelihood, evolutionary distance, and maximum parsimony methods. Mol Biol Evol. 2011;28:2731-9.

105. Jukes TH, Cantor CR. Evolution of protein molecules. In: Munro HN, editor. Mammalian protein metabolism. New York: Academic Press; 1969. p. 21-132

106. Baldo L, Bordenstein S, Wernegreen JJ, Werren JH. Widespread recombination throughout Wolbachia genomes. Mol Biol Evol. 2006b;23:437-49.

107. Kageyama D, Anbutsu H, Watada M, Hosokawa T, Shimada M, Fukatsu T. Prevalence of a non-male-killing Spiroplasma in natural populations of Drosophila hydei. Appl Environ Microb. 2006;72:6667-73.

108. Zchori-Fein E, Perlman SJ. Distribution of the bacterial symbiont Cardinium in arthropods. Mol Ecol. 2004;13:2009-16.

109. Sakurai M, Koga R, Tsuchida T, Meng XY, Fukatsu T. Rickettsia symbiont in the pea aphid Acyrthosiphon pisum: novel cellular tropism, effect on host fitness, and interaction with the essential symbiont Buchnera. App Environ Microbiol. 2005:71:4069-75.

110. Duron O, Bouchon D, Boutin S, Bellamy L, Zhou L, Engelstädter J, et al. The diversity of reproductive parasites among arthropods: Wolbachia do not walk alone. BMC Biol. 2008;6:27

111. Zchori-Fein E, Brown JK. Diversity of prokaryotes associated with Bemisia tabaci (Gennadius) (Hemiptera: Aleyrodidae). Ann Entomol Soc Am. 2002;95:711-8.

112. Segura DF, Utgés ME, Liendo MC, Rodríguez MF, Devescovi F, Vera MT, et al. Methoprene treatment reduces the pre-copulatory period in Anastrepha fraterculus (Diptera: Tephritidae) sterile males. J Appl Entomol. 2013;137(s1):19-29.

113. Bachmann GE, Segura DF, Devescovi F, Juárez ML, Ruiz MJ, Vera MT, et al. Male sexual behavior and pheromone emission is enhanced by exposure to guava fruit volatiles in Anastrepha fraterculus. PLoS One. 2015;10:e0124250.

114. StatSoft Inc, STATISTICA for Windows. 2000. Tulsa, OK, USA. http://www. statsoft.com.

115. Martínez I, Hernández-Ortiz V, Luna R. Desarrollo y maduración sexual en Anastrepha serpentina (Wiedemann) (Diptera: Tephritidae). Acta Zool Mex. 1995;65:75-88

116. Bartolucci AF, Vera MT, Yusef V, Oviedo A. Morphological characterization of the reproductive system of irradiated Anastrepha fraterculus. In Proc 7th Int Symp Fruit Flies Econ Importance 10-15 Sept 2006. Salvador: Color Press; 2006. p. 45-52.

117. Coscrato VE, Braz AS, Perondini AL, Selivon D, Marino CL. Wolbachia in Anastrepha fruit flies (Diptera: Tephritidae). Curr Microbiol. 2009:59:295-301.

118. Mascarenhas RO, Prezotto LF, Perondini ALP, Marino CL, Selivon D. Wolbachia in guilds of Anastrepha fruit flies (Tephritidae) and parasitoid wasps (Braconidae). Genet Mol Biol. 2016:39:600-10.

119. Veneti Z, Clark ME, Zabalou S, Karr TL, Savakis C, Bourtzis K. Cytoplasmic incompatibility and sperm cyst infection in different Drosophila-Wolbachia associations. Genetics. 2003;164:545-52.

120. Jeyaprakash A, Hoy MA. Long PCR Improves Wolbachia DNA amplification: wsp sequences found in $76 \%$ of sixty-three arthropod species. Insect Mol Biol 2000;9:4:393-405.
121. Arthofer W, Riegler M, Schneider D, Krammer M, Miller WJ, Stauffer C. Hidden Wolbachia diversity in field populations of the European cherry fruit fly, Rhagoletis cerasi (Diptera, Tephritidae). Mol Ecol. 2009;18:3816-30.

122. Zchori-Fein E, Bourtzis K. Manipulative tenants: bacteria associated with arthropods. CRC Press Taylor and Francis Group, LLC, Florida, USA , 2011. p. 268.

123. Schneider DI, Klasson L, Lind AE, Miller WJ. More than fishing in the dark: PCR of a dispersed sequence produces simple but ultrasensitive Wolbachia detection. BMC Microbiol. 2014;14:121.

124. Mee PT, Weeks AR, Walker PJ, Hoffmann AA, Duchemin JB. Detection of low-level Cardinium and Wolbachia infections in Culicoides. Appl Environ Microbiol. 2015;81:6177-88.

125. Kageyama D, Yoshimura K, Sugimoto TN, Katoh TK, Watada M. Maternally transmitted non-bacterial male killer in Drosophila biauraria. Biol Lett. 2017; 13:20170476.

126. Kageyama D, Traut W. Opposite sex-specific effects of Wolbachia and interference with the sex determination of its host Ostrinia scapulalis. Proc $R$ Soc Lond B Biol Sci. 2004;271:251-8.

127. Poinsot D, Bourtzis K, Markakis G, Savakis C, Merçot H. Wolbachia transfer from Drosophila melanogaster into D. simulans: host effect and cytoplasmic incompatibility relationships. Genetics. 1998;150:227-37.

128. Lanzavecchia SB, Juri M, Bonomi A, Gomulski L, Scannapieco AC, Segura DF, et al. Microsatellite markers from the 'South American fruit fly' Anastrepha fraterculus: a valuable tool for population genetic analysis and SIT applications. BMC Genet. 2014;15:2-S13.

129. Parreño MA, Scannapieco AC, Remis MI, Juri M, Vera MT, Segura DF, et al. Dynamics of genetic variability in Anastrepha fraterculus (Diptera: Tephritidae) during adaptation to laboratory rearing conditions. BMC Genet. 2014;15:S14

\section{Publisher's Note}

Springer Nature remains neutral with regard to jurisdictional claims in published maps and institutional affiliations.
Ready to submit your research? Choose BMC and benefit from:

- fast, convenient online submission

- thorough peer review by experienced researchers in your field

- rapid publication on acceptance

- support for research data, including large and complex data types

- gold Open Access which fosters wider collaboration and increased citations

- maximum visibility for your research: over $100 \mathrm{M}$ website views per year

At $\mathrm{BMC}$, research is always in progress.

Learn more biomedcentral.com/submissions 